\title{
Evaluation of wound healing effects of ginsenoside Rg1 and red ginseng extract in STZ-induced diabetic wound model: an in vivo pilot study
}

Ji Yun Lim, MS ${ }^{1, \# a}$, Young Suk Choi, PhD ${ }^{1, \# a}$, Hye Rim Lee, BS ${ }^{1, \# a}$, Hye Min An, BS ${ }^{1, \# a,}$ Young Koo Lee, $\mathrm{MD}, \mathrm{PhD}^{2, *}$

7

$8 \quad{ }^{1}$ Hyangseol Clinical Laboratory, Soonchunhyang University, Asan, Republic of Korea.

${ }^{2}$ Department of Orthopedic Surgery, Soonchunhyang University Bucheon Hospital, Republic of Korea.

\section{First author: Ji Yun Lim, MS ${ }^{1, \# a}$}

${ }^{1}$ Department of Medical Sciences, Graduate School, Soonchunhyang University, Soonchunhyang-ro, Sinchang-myeon, Asan-si, Chungcheongnam-do, Republic of Korea.

\#aCurrent Address: Departments of Orthopedic Surgery, Soonchunhyang University, Bucheon Hospital, Jomaru-ro, Bucheon-si, Gyeonggi-do, Republic of Korea, Republic of Korea.

\section{E-mail: wldbsd174@naver.com}

\section{Co-author: Young Suk Choi, PhD ${ }^{1, \# a}$}

${ }^{1}$ Department of Medical Sciences, Graduate School, Soonchunhyang University, Soonchunhyang-ro, Sinchang-myeon, Asan-si, Chungcheongnam-do, Republic of Korea.

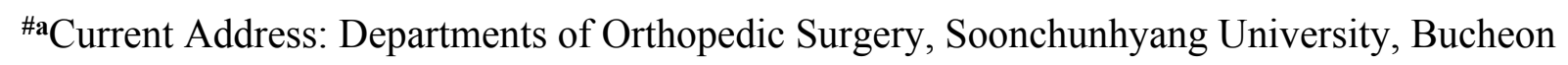


Hospital, Jomaru-ro, Bucheon-si, Gyeonggi-do, Republic of Korea, Republic of Korea.

E-mail: imysuk@hanmail.net

27

\section{Co-author: Hye Rim Lee, BS 1 ,\#a}

${ }^{1}$ Department of Medical Sciences, Graduate School, Soonchunhyang University,

Soonchunhyang-ro, Sinchang-myeon, Asan-si, Chungcheongnam-do, Republic of Korea.

${ }^{\# \text { Ca }}$ urrent Address: Departments of Orthopedic Surgery, Soonchunhyang University, Bucheon

Hospital, Jomaru-ro, Bucheon-si, Gyeonggi-do, Republic of Korea, Republic of Korea.

E-mail: freehaerim@naver.com

\section{Co-author: Hye Min An, BS ${ }^{1, \# a}$}

${ }^{1}$ Department of Medical Sciences, Graduate School, Soonchunhyang University,

\#a Current Address: Departments of Orthopedic Surgery, Soonchunhyang University, Bucheon

Hospital, Jomaru-ro, Bucheon-si, Gyeonggi-do, Republic of Korea, Republic of Korea.

E-mail: ahm112597@naver.com

\section{Corresponding author: Young Koo Lee, MD, PhD',**}

${ }^{2}$ Departments of Orthopedic Surgery, Soonchunhyang University, Bucheon Hospital, Jomaruro, Bucheon-si, Gyeonggi-do, Republic of Korea.

47 E-mail address: brain0808@hanmail.net (Y.-K. Lee).

ORCID: 0000-0002-3352-0278 


\section{Authors' contributions}

51 Ji Yun Lim is the first author, performed the experiments, and was responsible for the overall

52 writing and revision of the manuscript. Young Suk Choi, Hye Rim Lee, and Hye Min An are

53 co-authors, analyzed the result data and performed parts of the experiments. Young Koo Lee

54 is a corresponding author, played a role in interpreting the results, and gave final approval.

55 


\section{Abstract}

58

Red ginseng is an immune-enhancing compound that exhibits anti-inflammatory action. The ginsenoside $\mathrm{Rg} 1$, an ingredient of red ginseng, has been shown to play an important role in tumor suppression, wound healing, and angiogenesis. This study evaluated the effects of red ginseng extract and Rg1 in a diabetic wound model. Diabetes was induced with streptozotocin (STZ) in 8-week-old male Institute of Cancer Research (ICR) mice weighing 30-35 g. A fullthickness skin defect was treated by applying a dressing every 3 days. The mice were divided into three groups. Group 1 was administered an extract of red ginseng $(10 \mathrm{mg} / \mathrm{kg} / \mathrm{d}, n=27$, oral $)$ and group 2 was administered $\operatorname{Rg} 1(10 \mathrm{mg} / \mathrm{kg} / \mathrm{d}, n=27$, oral). Group 3 was a control group treated with phosphate-buffered saline $(0.3 \mathrm{~mL} / \mathrm{kg} / \mathrm{d}, n=27$, oral $)$. Red ginseng extract and $\operatorname{Rg} 1$ were orally administered to mice daily for 10 days following injury in groups 1 and 2, respectively. Both increased mRNA and protein levels of vascular endothelial growth factor (VEGF) and transforming growth factor (TGF)- $\beta 1$ compared to controls. In addition, the wounds of animals in the $\operatorname{Rg} 1$ group were significantly smaller between days 7 and 10 $(p<0.05)$. VEGF and TGF- $\beta 1$ were not expressed in diabetic mice in the control group. Both red ginseng extract and Rg1 promoted the production of VEGF and TGF- $\beta 1$, which are important in wound healing. Our results for $\operatorname{Rg} 1$ suggest its potential to promote diabetic wound healing by stimulating the production or activity of VEGF and TGF- $\beta 1$ factors involved in the wound healing process.

\section{Keywords}

Ginsenoside Rg1, Red ginseng extract, Growth factor, Diabetic wound, Diabetes 


\section{Introduction}

By the year 2035, it is expected that 592 million people will suffer from diabetes, making it one of the most important medical issues globally [1]. Diabetes is divided into two types: type 1 diabetes (T1D) is characterized by impaired pancreatic $\beta$-cell function resulting in insulin deficiency and chronic hyperglycemia while type 2 diabetes (T2D) is characterized by insulin resistance and hyperglycemia [2]. Chronic hyperglycemia causes deterioration of blood vessels and nerves, resulting in cardiovascular diseases and neuropathy [3, 4]. Additional complications, such as diabetic wounds, impair the four stages of wound healing (e.g., hemostasis, inflammation, proliferation and remodeling), delaying the healing process [5]. As a result, chronic wounds in diabetic patients damage wounds and surrounding tissues due to excessive inflammatory reactions, and delay wound healing through delayed expression of growth factors. In serious cases, this results in loss of the affected limb or death $[6,7]$. However, a detailed understanding of the delayed healing of diabetic wounds is lacking and current forms of treatment such as oral antidiabetics and insulin injection, have many unwanted side effects, such as hypertension, weight gain, and endothelial cell damage $[8,9]$. This has stimulated the search for safe and effective treatments. Panax ginseng is one of the oldest traditional herbs and it contains approximately 32 species of ginsenosides [10]. In recent years, ginsenosides have been demonstrated to exhibit many properties, including immune-stimulating activity and anticancer, anti-inflammatory, antiallergic, antihypertensive, and antidiabetic effects [11]. Ginsenosides with antidiabetic effects include $\mathrm{Rg} 1, \mathrm{Rg} 3, \mathrm{Rg} 5, \mathrm{Rb} 1, \mathrm{Rb} 2$, and $\mathrm{Rb} 3$, and ginsenosides have been used as an adjuvant for the treatment of diabetes because they exhibit antidiabetic effects [12]. Of the many types of saponins, the ginsenoside Rg1 reduces intestinal glucose uptake by inhibiting the expression of the $\mathrm{Na}^{+}$/glucose cotransporter 1 (SGLT1) gene 
responsible for glucose uptake in intestinal epithelial cells [13]. Rg1 has been proposed to reduce oxidative stress and cardiomyocyte death and prevent cardiovascular damage in diabetic mice [14]. $\operatorname{Rg} 1$ is also excellent for skin regeneration [15]. Representative factors involved in wound healing include transforming growth factor (TGF)- $\beta$, fibroblast growth factor (FGF), and vascular endothelial growth factor (VEGF). VEGF plays an important role in wound healing, and participates in endothelial migration, proliferation, and granulation tissue and blood vessel formation. TGF- $\beta$ promotes wound healing, fibroblast proliferation, and expression of major components of the extracellular matrix such as fibronectin, collagen I and III, and VEGF [16]. Although wounds heal as the expression of these growth factors gradually increases, the roles of these factors throughout the healing process have not been fully clarified [17]. The use of $\operatorname{Rg} 1$ in wound healing and angiogenesis is being actively studied [18,19], although neither its effect nor that of red ginseng on diabetic wounds is known. Therefore, the purpose of this pilot study was to evaluate the effects of red ginseng extract and $\operatorname{Rg} 1$ in a streptozotocin (STZ)-induced type 1 diabetic mouse wound model. The main hypothesis of this pilot study was that the expression of VEGF and TGF- $\beta 1$ in animal models treated with red ginseng extract and $\operatorname{Rg} 1$ is important in wound healing.

\section{Materials and methods}

\section{Animal model}

Male Institute of Cancer Research (ICR) mice aged 6 to 8 weeks (30-35 g) were purchased from Orient BIO Inc. (Seongnam, Korea). All mice were allowed to adjust to the environment for 1 week prior to the experiment. The mice were housed in cages with a $12 \mathrm{~h} / 12 \mathrm{~h}$ light/dark cycle at $23 \pm 2{ }^{\circ} \mathrm{C}$ and $50 \pm 20 \%$ humidity with freely available water and rodent chow (LabDiet 
5L 79 ${ }^{\circledR}$; Orient BIO Inc.). The experimental design was approved by the Institutional Animal

Diabetes was induced by intraperitoneal (IP) injection of $100 \mathrm{mg} / \mathrm{kg}$ STZ (S0130; Sigma-

After $24 \mathrm{~h}$, blood was collected from the tail vein and blood glucose levels were measured using the Accu-Chek ${ }^{\circledR}$ system (Roche Diagnostics, Mannheim, Germany). Diabetes was defined as a blood glucose level greater than $200 \mathrm{mg} / \mathrm{dL}$ after STZ injection. The mice were anesthetized by IP injection of zolazepam/tiletamine (Zoletil 50 ${ }^{\circledR}$; Virbac, Carros, France) and xylazine (Rompun ${ }^{\circledR}$; Bayer Korea, Seoul, Korea). The hairs on the back of the mice were shaved, the exposed skin was cleansed with $70 \%$ ethanol, and a full-thickness skin defect wound of $8 \mathrm{~mm}$ in diameter was made using a sterile skin biopsy punch (BP-80F; Kai Industries, Gifu, Japan). The methicillin-resistant Staphylococcus aureus (MRSA) standard strain (ATCC ${ }^{\circledR} ; 43300$ MINIPACK ${ }^{\mathrm{TM}}$, Manassas, VA, USA) was incubated overnight at $37^{\circ} \mathrm{C}$ on Mueller - Hinton agar plates. MRSA was diluted in sterilized saline to adjust to McFarland 0.5 standard turbidity and applied to the skin defects. Vaseline (Samhyun Pharmaceutical,

Seoul, Korea) was applied to all wounds using a gauze pad to prevent the wound from drying.

145 Then the wounds were covered with Opsite-film (Opsite Flexifix ${ }^{\circledR}$; Smith \& Nephew Medical Ltd., Hull, UK) dressings. The dressings were replaced every 3 days. 
STZ-induced diabetic mice were orally administered $10 \mathrm{mg} / \mathrm{kg}$ of red ginseng extract or $\mathrm{Rg} 1$

Ginseng Research Institute, Daejeon, Korea) and the ginsenoside Rg1 (purity > 98\%; 22427-

induced diabetic mice $(n=81)$ were randomly divided into three different treatment groups as

follows: PBS $(0.3 \mathrm{~mL} / \mathrm{kg} / \mathrm{d}, n=27$, oral $)$, red ginseng extract $(10 \mathrm{mg} / \mathrm{kg} / \mathrm{d}, n=27$, oral $)$, and

$\operatorname{Rg} 1(10 \mathrm{mg} / \mathrm{kg} / \mathrm{d}, n=27$, oral). Treatments were administered orally once daily for 10 days

following induction of injury (Figure 1).

\section{Measurement of wound area}

Images of the skin wound were obtained on days 1, 4, 7, and 10 and the wound size was

measured using the UTHSCSA image tool (version 3.0; Microsoft Corporation, Redmond, WA,

USA). The wound size on the first day after wound induction was defined as $100 \%$ and wound

sizes measured on days 4, 7, and 10 are expressed as a percentage of wound size at day 1 .

\section{Histological analyses of diabetic wound tissue}

Wound tissues were compared in the three groups by euthanizing the mice at days $1,4,7$, and 10 after injury. The skin tissues were harvested to include the entire wound, fixed for $12 \mathrm{~h}$ in 4\% paraformaldehyde prepared in PBS (pH 7.4; Santa Cruz Biotechnology, Dallas, TX, USA), washed with PBS at room temperature for $6 \mathrm{~h}$, and processed overnight in an automatic tissue processor. Sections of $4 \mu \mathrm{m}$ thickness were cut, placed on coated glass slides (5116-20F; Muto Pure Chemicals Co., Ltd., Tokyo, Japan), and deparaffinized before staining with hematoxylin 
and eosin (H\&E; Gills hematoxylin, 1\% eosin; Muto Pure Chemicals Co., Ltd.). Three pathologists blinded to the three groups scored the tissues according to Tables 1 and 2 based on light microscopy (DXM1200; Nikon, Tokyo, Japan) images of the sections at 200× magnification. These images were assessed for granulation tissue area, inflammatory cells, connective tissue, and damage to the dermal layer.

\section{Expression of VEGF and TGF- $\beta 1$ in diabetic wound tissue by immunohistochemistry}

The paraffin-embedded wound tissue blocks were sectioned, placed on slides, and incubated at $60-70^{\circ} \mathrm{C}$ for $30 \mathrm{~min}$. The sections were deparaffinized in a graded series of xylene and ethanol $(100 \%, 95 \%, 80 \%$, and $70 \%)$ and treated with an endogenous peroxidase blocking agent, which then was diluted with methanol $(99 \%)$ and a $1.4 \%$ hydrogen peroxide solution $(\mathrm{FW}=34.01)$. After $30 \mathrm{~min}$, the slides were washed with $1 \times$ Tris-buffered saline (TBS) and sections were blocked with 1.5\% normal serum (PK-6102, horse serum, mouse IgG or PK-6101, goat serum rabbit IgG; Vector Laboratories, Burlingame, CA, USA) for $1 \mathrm{~h}$ followed by incubation overnight at $4^{\circ} \mathrm{C}$ with anti-VEGF monoclonal antibody (SC-7269, 1:500 dilution; Santa Cruz Biotechnology) and anti-TGF- $\beta 1$ polyclonal antibody (ab92486, 1:1000 dilution; Abcam) in blocking buffer. Then the samples were washed with $1 \times$ TBS followed by incubation for $1 \mathrm{~h}$ at room temperature with a biotinylated secondary antibody (PK-6102, horse serum, mouse IgG or PK-6101, goat serum rabbit IgG; 1:3000 dilution; Vector Laboratories) in blocking buffer, and washed again with $1 \times$ TBS. Incubation with the VECTASTAIN Elite avidin-biotin complex (PK-6102 or PK-6101; Vectastain $\AA$; Vector Laboratories) was used to increase the target antigen-antibody reaction during a 30 min incubation. Then the sections were stained with the chromogen diaminobenzidine (C02-100; Liquid DAB + Chromogen Kit; Golden 
Bridge International Inc., Mukilteo, WA, USA) for 5-6 min followed by hematoxylin for $1 \mathrm{~min}$ before they were covered with a coverslip and evaluated using a digital microscope (DXM1200; Nikon) at $200 \times$ magnification.

\section{Reverse transcription-polymerase chain reaction (RT-PCR)}

Total RNA was isolated from wounded skin tissue samples using TRIzol Reagent ${ }^{\circledR}$ (TR118; Molecular Research Center, Cincinnati, OH, USA). mRNA was isolated using chloroform and isopropanol (C2432, I9516; Sigma-Aldrich). After precipitation with isopropanol, the RNA pellet was dissolved in distilled water treated with diethyl pyrocarbonate (DEPC; WR2004; Biosesang, Sungnam, Korea). Total RNA was quantified to $3 \mu \mathrm{g}$ to react $1 \mu \mathrm{g} / \mu \mathrm{L}$ random hexamer (C1181; Promega, Madison, WI, USA) at $70^{\circ} \mathrm{C}$ for $5 \mathrm{~min}$, then incubated at $4{ }^{\circ} \mathrm{C}$ for $5 \mathrm{~min}$. Each reaction contained $1 \mu \mathrm{L}$ of $10 \mathrm{mM}$ dNTPs, $1 \mu \mathrm{mol} / \mathrm{L} \mathrm{MgCl}_{2}, 1 \mu \mathrm{g} / \mu \mathrm{L}$ RNaseOUT, $1 \mu \mathrm{g} / \mu \mathrm{L} 5 \times$ reaction buffer, $1 \mu \mathrm{L}$ GoScript reverse transcriptase (A5003; Promega), and $7 \mu \mathrm{L}$ RNase-free double-distilled $\mathrm{H} 2 \mathrm{O}\left(\mathrm{N} 2511\right.$; Promega) and was incubated at $25^{\circ} \mathrm{C}$ for $5 \mathrm{~min}$, followed by incubation at $42^{\circ} \mathrm{C}$ for $1 \mathrm{~h}$ and $70^{\circ} \mathrm{C}$ for $15 \mathrm{~min}$. The VEGF, TGF- $\beta 1$, and glyceraldehyde-3-phosphate dehydrogenase (GAPDH) primer gene sequences were as follows:

VEGF forward primer, 5' - CAG GCT GCT GTA ACG ATG AA -3'; VEGF reverse primer, 5'- AAT GCT TTC TCC GCT CTG A -3'; TGF- $\beta 1$ forward primer, 5'- ATT CAG CGC TCA CTG CTC TT-3'; TGF- $\beta 1$ reverse primer, 5'- TTC TCT GTG GAG CTG AAG CA-3'; and GAPDH forward primer, 5' - CCT TAA ACA GGC CCA CTT GA-3'; GAPDH reverse primer, 5' - CCT TCC ACA ATG CCA AAG TT-3' (Table 1). All primers were ordered from 
216 Macrogen Oligo (Seoul, Korea). PCR was performed using $1 \mu \mathrm{L}$ cDNA in a mixture with $2 \times$

217 PCR premix (LGT-1212; Lugen Science Co., Seoul, Korea). The conditions for VEGF

218 included initial denaturation at $95^{\circ} \mathrm{C}$ for $5 \mathrm{~min}$, melting at $95^{\circ} \mathrm{C}$ for $30 \mathrm{~s}$, annealing at $60^{\circ} \mathrm{C}$ for

$2191 \mathrm{~min}$, and elongation at $72^{\circ} \mathrm{C}$ for $30 \mathrm{~s}$. For TGF- $\beta 1$ and GAPDH, annealing was performed at

$22058^{\circ} \mathrm{C}$ for 30 s. PCR products were visualized using a bioimaging system (C280; Azure

221 Biosystems, Dublin, CA, USA) after electrophoresis on a 1\% agarose gel containing Safe Shine

222 Green DNA Staining Solution (GC6051; Biosesang). GAPDH was selected for normalization

223 of specific primer target bands, and density measurements of the target bands were analyzed

224 with ImageJ software (National Institutes of Health, Bethesda, MD, USA).

Western blot analysis

227

The skin tissue was homogenized using complete EDTA free protease inhibitor cocktail

(11836170001; Roche Diagnostics GmbH), phosSTOP phosphatase inhibitor (30498800;

Roche Diagnostics GmbH), and RIPA buffer (R4200; GenDEPOT, Barker, TX, USA).

Dissolved protein was analyzed for protein concentration by micro-scale BCA assay (Micro

BCA Protein Assay Kit \#23225; Thermo Fisher Scientific Inc., Waltham, MA, USA). Lysates electrophoresis (SDS-PAGE) and transferred to a polyvinylidene difluoride membrane (10600023; GE Healthcare Life Sciences, Chalfont, UK). After blocking with 5\% skim milk (232100; Becton Dickinson, Franklin Lakes, NJ, USA) at $4^{\circ} \mathrm{C}$ for $24 \mathrm{~h}$, the membranes were incubated with anti-VEGF monoclonal antibody (SC-7269; 1:500 dilution; Santa Cruz

237 Biotechnology), anti-TGF- $\beta 1$ polyclonal antibody (ab92486; 1:1000 dilution; Abcam), and $\beta$ actin rabbit antibody (4970S; 1:5000 dilution; Cell Signaling, Beverly, MA, USA) at room 
temperature for $2 \mathrm{~h}$ followed by the appropriate secondary antibody (SC-2005; 1:3000 dilution;

Healthcare Life Sciences) and a bioimaging system (C280; Azure Biosystems). The band intensities were normalized with $\beta$-actin and the density measurements were analyzed with

ImageJ software (National Institutes of Health).

Statistical analysis

The data were analyzed using SPSS version 22.0 (SPSS Inc., Chicago, IL, USA) and the Mann-

Whitney U test. All $p$-values less than 0.05 were considered statistically significant.

\section{Results}

\section{Wound size measurement}

In each group, the wound size decreased over time (Figure 2A). On day 4, there was larger group (Figure 2B).

Histology and immunohistochemistry analyses

The central portion of the wounded tissues was collected to evaluate granulation tissue formation, inflammatory cell infiltration, and growth factor expression. The wound healing 
effects of the red ginseng extract and $\mathrm{Rg} 1$ groups were evaluated histologically. Samples of all groups exhibited histological patterns of dermal tissue (consisting of three layers of epidermis, dermis, and subcutaneous tissue). H\&E and immunohistochemistry (IHC) staining were performed (Figure 3A-C). The degree of granulation and inflammatory cell infiltration was not different in the three groups at day 4 . However, at day 10, granulation tissue was formed in the

Rg1 group whereas the control group remained unchanged $(p<0.05)$. On the other hand, inflammatory cell infiltration in the $\mathrm{Rg} 1$ group was significantly lower at day 10 compared to the other two groups $(p<0.05)$ (Figure 3D, E). Expression of VEGF and TGF- $\beta 1$ was confirmed by IHC staining; VEGF was mainly present in granulation tissues and TGF- $\beta 1$ was observed on the wound surface.

We investigated the effects of wound healing on mRNA expression of VEGF and TGF- $\beta 1$ in a diabetic wound model. GAPDH was used to normalize the expression level of specific target bands (Figure 4A). At day 7, mRNA expression of VEGF and TGF- $\beta 1$ was significantly increased in the red ginseng extract group $(p<0.05)$ and decreased at day 10 . The expression of VEGF in the Rg1 group significantly increased on days 4-10 $(p<0.05)$. Expression of TGF$\beta 1$ was observed from day 4 in the red ginseng extract group but gradually increased on days 7-10 in the Rg1 group. In the control group, the expression of VEGF and TGF- $\beta 1$ was delayed (Figure 4B-C).

Protein levels of VEGF and TGF- $\beta 1$ were observed by western blotting; $\beta$-actin was used to 
normalize the expression level of specific target bands (Figure 5A). VEGF expression was significantly increased $(p<0.05)$ in the red ginseng extract and $\operatorname{Rg} 1$ groups at days $4-7$, but decreased significantly at day 10 in the $\operatorname{Rg} 1$ group $(p<0.05)$. The expression of TGF- $\beta 1$ was significantly higher on days 4-7 in the red ginseng extract group than in the other groups $(p<0.05)$ and decreased on days $7-10$. In the control group, VEGF tended to increase over time, but TGF- $\beta 1$ expression did not (Figure 5B-C).

\section{Discussion}

This study indicates that administration of red ginseng extract and $\mathrm{Rg} 1$ can regulate the healing of diabetic wounds. Red ginseng extract and $\mathrm{Rg} 1$ have antidiabetic and wound healing effects on normal wounds $[21,22]$, but the effects on diabetic wound animal models have not been confirmed. This study showed that administration of red ginseng extract and $\operatorname{Rg} 1$ increases the expression of VEGF and TGF- $\beta 1$, thereby promoting wound healing in an animal model of STZ-induced diabetic wounds (i.e., chronic wounds with delayed healing). Wound healing is generally divided into four stages: hemostasis, inflammation, proliferation, and remodeling. The first stage is hemostasis and clotting [23]. When this process begins, various immune cells such as platelets, neutrophils, and monocytes, as well as growth factors, such as platelet-derived growth factor (PDGF) and TGF- $\beta$, are expressed. Inflammatory processes produce neutrophils, macrophages, and inflammatory cytokines following tissue damage [24]. Some growth factors, such as PDGF, epidermal growth factor (EGF), and VEGF, are also expressed; however, in diabetic patients, due to this imbalance of cytokines, would healing does not follow the four general stages $[25,26]$, resulting in delayed healing. Rg1 not only lowers blood sugar but also increases the expression of factors involved in wound healing, thus promoting wound healing 
in mice [27, 28]. Kim et al. [29]. reported that RG promotes angiogenesis by stimulating VEGF and improves the proliferation of epidermal cells by upregulating cytokine expression in keratinocytes. These results suggest that RG accelerates the wound-healing process by increasing TGF- $\beta$ and VEGF expression in the early stages of wound healing [30]. Diabetes is characterized by the overexpression of factors such as nuclear factor- $\kappa \mathrm{B}$ as well as proinflammatory mediators, cytokines, and nitric oxide (NO), which increase intracellular oxidative stress due to insulin resistance and hyperglycemia, resulting in abnormal cells and inhibition of angiogenesis [31]. In addition, high glucose-derived reactive oxygen species affect the onset of diabetic complications [32]. Recent studies have shown that growth-factor regulatory defects in wounds in both diabetic models and diabetic patients exacerbate woundhealing disorders $[33,34]$. Although prophylactic treatment with red ginseng contributes to wound healing by controlling the expression of VEGF and TGF- $\beta 1$, excessive expression can lead to chronic inflammation and negatively affect wound healing $[35,36,37]$. Therefore, it is important to evaluate the inflammatory response in diabetic wounds and the underlying molecular mechanisms of growth factors. In the present study, we examined whether the administration of red ginseng extract and Rg1 affects expression of VEGF and TGF- $\beta 1$ in a diabetic wound model. Our results provide evidence of the wound healing effects of red ginseng extract and $\operatorname{Rg} 1$ on the diabetic wound model. To determine whether red ginseng extract and $\operatorname{Rg} 1$ are effective for wound healing at mRNA and protein levels, we confirmed the expression of VEGF and TGF- $\beta 1$ by RT-PCR and western blotting. Treatment with Rg1 in a diabetic wound model with delayed wound healing resulted in upregulated mRNA expression level of VEGF and TGF- $\beta 1$ from the wound-healing inflammation phase to the proliferation 
after the injury), resulting in downregulation of expression at day 10 after the wound was fully healed (Figure 5). Other studies have shown that treatment with Rg1 increases angiogenesis and insulin secretion by increasing VEGF expression in the proliferative phase and progressively decreasing VEGF expression over time [38, 39]. In particular, Rg1 treatment reduced wound size compared to the control group (red ginseng extract, $\operatorname{Rg} 1$, and control mice were all diabetic). Factors such as TGF- $\beta$, PDGF, and interleukin (IL)-1 produced by T cells and macrophages stimulate a variety of growth factors; the expression of VEGF during the inflammatory stage also plays an important role in wound healing [40, 41, 42]. VEGF is an angiogenic cytokine that contributes to the proliferation phase of wound healing by promoting angiogenesis and the formation of fibrous cells, collagen, and granulation tissue around the wound $[43,44]$. Many studies have focused on VEGF as a factor promoting angiogenesis and its role in various diseases $[45,46]$. In the remodeling phase, VEGF induces cell degranulation, fibroblast proliferation, and migration of existing blood vessels by proteases; fibroblasts are transformed into $\alpha$-smooth muscle actin bundles similar to smooth muscle cells, resulting in contraction of the wound [47, 48]. Nogami et al. [49] reported that VEGF mRNA levels were reduced significantly in diabetic animal models compared to normal models; thus, regulatory defects in VEGF delayed wound healing. Our results also showed that both red ginseng extract and Rg1 were affected by a delayed wound healing due to a lack of VEGF and TGF- $\beta 1$ expression in untreated diabetic wounds (i.e., in the control group). In our histological analyses, both red ginseng and $\operatorname{Rg} 1$ treatment promoted formation of granulation tissue at days 7-10 after injury; wound contraction, reduction of inflammatory cells, and promotion of growth factors were observed during reconstruction at day 10. Treatment of tissues with $\operatorname{Rg} 1$ contributes to wound healing by promoting collagen production and VEGF expression [50, 
expression in diabetic wounds. Similarly, our results suggest that treatment with red ginseng and TGF- $\beta 1$; growth factors were also expressed at the inflammatory stage, promoting proliferation (Figure 3). This is the first report to show that red ginseng extract and Rg1 regulate the expression of VEGF and TGF- $\beta 1$ to induce healing of diabetic wounds. Expression levels of these factors were confirmed by histological staining, IHC, and molecular biology.

\section{Conclusion}

Rg1 treatment increases the expression of VEGF and TGF- $\beta 1$, which are important for wound healing in STZ-induced diabetic wounds. Rg1 can improve diabetic wound healing by stimulating the production or activity of factors related to wound healing.

\section{Limitations}

Although factors such as STZ can cause T1D, T2D is a complex metabolic disorder due to insulin resistance driven by environmental factors (e.g., obesity, and age). Additionally, animal experiments may not reflect all clinically observed complexities associated with disease [52]. Further studies of T2D may provide clinical data to corroborate the results obtained in this study.

\section{Acknowledgments}

375 This research was supported by the Basic Science Research Program through the National

376 Research Foundation of Korea (NRF) funded by the Ministry of Education (grant number 377 2019-061364) and the Soonchunhyang University research fund. 
379 Availability of data and materials

380 All study data used to support our findings are available from the corresponding authors upon

381 request.

382

383 Ethics approval and consent to participate: All procedures involving animals were in accordance with the ethical standards of the institution. The experimental design was approved 


\section{References}

403

404 1. Dagogo-Jack S. Diabetes mellitus in developing countries and underserved

405 communities: Springer; 2017.

4062 2. Association AD. Diagnosis and classification of diabetes mellitus. Diabetes care.

$407 \quad 2014 ; 37($ Supplement 1):S81-S90.

408 3. Di Carli MF, Janisse J, Ager J, Grunberger G. Role of chronic hyperglycemia in the

409 pathogenesis of coronary microvascular dysfunction in diabetes. Journal of the American

410 College of Cardiology. 2003;41(8):1387-93.

411 4. Juster-Switlyk K, Smith AG. Updates in diabetic peripheral neuropathy.

412 F1000Research. 2016;5.

413 5. Patel S, Srivastava S, Singh MR, Singh D. Mechanistic insight into diabetic wounds:

414 Pathogenesis, molecular targets and treatment strategies to pace wound healing. Biomedicine

415 \& Pharmacotherapy. 2019;112:108615.

416 6. Chawla A, Chawla R, Jaggi S. Microvasular and macrovascular complications in

417 diabetes mellitus: distinct or continuum? Indian journal of endocrinology and metabolism.

$418 \quad 2016 ; 20(4): 546$.

419 7. Gill G, Famuyiwa O, Rolfe M, Archibald L. Serious hand sepsis and diabetes

420 mellitus: specific tropical syndrome with western counterparts. Diabetic medicine.

$421 \quad 1998 ; 15(10): 858-62$.

422 8. Gupta R, Sharma AK, Dobhal M, Sharma M, Gupta R. Antidiabetic and antioxidant

423 potential of $\beta$-sitosterol in streptozotocin-induced experimental hyperglycemia. Journal of

424 diabetes. 2011;3(1):29-37.

425 9. Sebastião I, Candeias E, Santos MS, de Oliveira CR, Moreira PI, Duarte AI. Insulin

426 as a bridge between type 2 diabetes and Alzheimer disease-how anti-diabetics could be a

427 solution for dementia. Frontiers in endocrinology. 2014;5:110.

428 10. Kim HJ, Kwak I, Kim HJ, Ahn JS, Son YB. A study on the amendment scheme of 429 ginsenoside content standard regulation for red ginseng products in Korea. Journal of Food

430 Hygiene and Safety. 2013;28(1):24-30.

431 11. Christensen LPJAif, research n. Ginsenosides: chemistry, biosynthesis, analysis, and 432 potential health effects. 2008;55:1-99. 

as an adjuvant treatment for diabetes. Frontiers in pharmacology. 2018;9:423. role of cAMP response element binding protein in ginsenoside Rg1-mediated inhibition of $\mathrm{Na}+$ glucose cotransporter 1 gene expression. 2015;88(6):1072-83. 14. Yu H-t, Zhen J, Pang B, Gu J-n, Wu S-sJJoZU-SB. Ginsenoside Rg1 ameliorates oxidative stress and myocardial apoptosis in streptozotocin-induced diabetic rats. 2015;16(5):344-54.

441 15. Choi J-H, Oh S-K. Studies on the anti-aging action of Korean ginseng. Korean 442 Journal of Food Science and Technology. 1985;17(6):506-15. transforming growth factor beta in different phases of wound healing. 2013;2(5):215-24. 17. Barrientos S, Stojadinovic O, Golinko MS, Brem H, Tomic-Canic M. Growth factors and cytokines in wound healing. Wound repair and regeneration. 2008;16(5):585-601. 18. Yue PYK, Mak NK, Cheng YK, Leung KW, Ng TB, Fan DTP, et al. Pharmacogenomics and the Yin/Yang actions of ginseng: anti-tumor, angiomodulating and steroid-like activities of ginsenosides. Chinese medicine. 2007;2(1):1-21. 19. Savari R, Shafiei M, Galehdari H, Kesmati M. Expression of VEGF and TGF- $\beta$ genes in skin wound healing process induced using phenytoin in male rats. Jundishapur Journal of Health Sciences. 2019;11(1). cardiomyopathy by inhibiting endoplasmic reticulum stress-induced apoptosis in a streptozotocin-induced diabetes rat model. Journal of Cellular and Molecular Medicine. 2016;20(4):623-31. of total ginseng saponin on skin wound healing. Journal of ginseng research. 2011;35(3):360. 22. Mohanan P, Subramaniyam S, Mathiyalagan R, Yang D-C. Molecular signaling of

460 ginsenosides Rb1, $\mathrm{Rg} 1$, and $\mathrm{Rg} 3$ and their mode of actions. Journal of Ginseng Research. $461 \quad 2018 ; 42(2): 123-32$. dermatology. 2007;25(1):9-18. 
24. Nguyen TT, Mobashery S, Chang M. Roles of matrix metalloproteinases in cutaneous wound healing: InTech; 2016.

25. Lan CC, Liu IH, Fang AH, Wen CH, Wu CS. Hyperglycaemic conditions decrease cultured keratinocyte mobility: implications for impaired wound healing in patients with diabetes. British Journal of Dermatology. 2008;159(5):1103-15.

26. Werner S, Grose R. Regulation of wound healing by growth factors and cytokines. Physiological reviews. 2003;83(3):835-70.

27. Yang N, Chen P, Tao Z, Zhou N, Gong X, Xu Z, et al. Beneficial effects of ginsenoside-Rg1 on ischemia-induced angiogenesis in diabetic mice. Acta Biochim Biophys Sin. 2012;44(12):999-1005.

28. Kimura Y, Sumiyoshi M, Kawahira K, Sakanaka M. Effects of ginseng saponins isolated from Red Ginseng roots on burn wound healing in mice. British journal of Pharmacology. 2006;148(6):860-70.

29. Kim YG, Sumiyoshi M, Sakanaka M, Kimura Y. Effects of ginseng saponins isolated from red ginseng on ultraviolet B-induced skin aging in hairless mice. European journal of pharmacology. 2009;602(1):148-56.

30. Park K-S, Park D-H. The effect of Korean Red Ginseng on full-thickness skin wound healing in rats. Journal of ginseng research. 2019;43(2):226-35.

31. Kolluru GK, Bir SC, Kevil CG. Endothelial dysfunction and diabetes: effects on angiogenesis, vascular remodeling, and wound healing. International journal of vascular medicine. 2012;2012.

32. Panigrahy SK, Bhatt R, Kumar A. Reactive oxygen species: sources, consequences and targeted therapy in type 2 diabetes. Journal of drug targeting. 2017;25(2):93-101.

33. Dogan S, Demirer S, Kepenekci I, Erkek B, Kiziltay A, Hasirci N, et al. Epidermal growth factor-containing wound closure enhances wound healing in non-diabetic and diabetic rats. International wound journal. 2009;6(2):107-15.

34. Blakytny R, Jude E. The molecular biology of chronic wounds and delayed healing in diabetes. Diabetic Medicine. 2006;23(6):594-608.

35. Namgoong S, Lee H, Han SK, Lee HW, Jeong SH, Dhong ES. Effect of Panax ginseng extract on the activity of diabetic fibroblasts in vitro. International wound journal. 2019;16(3):737-45. 
36. Yang L, Chan T, Demare J, Iwashina T, Ghahary A, Scott PG, et al. Healing of burn wounds in transgenic mice overexpressing transforming growth factor- $\beta 1$ in the epidermis. The American journal of pathology. 2001;159(6):2147-57.

37. Schlingemann RO. Role of growth factors and the wound healing response in agerelated macular degeneration. Graefe's archive for clinical and experimental ophthalmology. 2004;242(1):91-101.

38. Bao P, Kodra A, Tomic-Canic M, Golinko MS, Ehrlich HP, Brem H. The role of vascular endothelial growth factor in wound healing. Journal of Surgical Research. 2009;153(2):347-58.

39. Goldman R. Growth factors and chronic wound healing: past, present, and future. Advances in skin \& wound care. 2004;17(1):24-35.

40. Kondo T, Ohshima T. The dynamics of inflammatory cytokines in the healing process of mouse skin wound: a preliminary study for possible wound age determination. International journal of legal medicine. 1996;108(5):231-6.

41. Pierce GF, Mustoe TA, Altrock BW, Deuel TF, Thomason A. Role of platelet-derived growth factor in wound healing. Journal of cellular biochemistry. 1991;45(4):319-26.

42. Enoch S, Leaper DJ. Basic science of wound healing. Surgery (Oxford). 2008;26(2):31-7.

43. Grazul-Bilska AT, Johnson ML, Bilski JJ, Redmer DA, Reynolds LP, Abdullah A, et al. Wound healing: the role of growth factors. Drugs Today (Barc). 2003;39(10):787-800.

44. Wilgus TA, DiPietro LA. Complex roles for VEGF in dermal wound healing. The Journal of investigative dermatology. 2012;132(2):493.

45. Khurana R, Simons M, Martin JF, Zachary IC. Role of angiogenesis in cardiovascular disease: a critical appraisal. Circulation. 2005;112(12):1813-24.

46. Pandya NM, Dhalla NS, Santani DD. Angiogenesis - a new target for future therapy. Vascular pharmacology. 2006;44(5):265-74.

47. Ellis S, Lin EJ, Tartar D. Immunology of wound healing. Current dermatology reports. 2018;7(4):350-8.

48. Goldberg MT, Han Y-P, Yan C, Shaw MC, Garner WL. TNF- $\alpha$ suppresses $\alpha$-smooth muscle actin expression in human dermal fibroblasts: an implication for abnormal wound 
526 healing. Journal of Investigative Dermatology. 2007;127(11):2645-55.

527 49. Nogami M, Hoshi T, Kinoshita M, Arai T, Takama M, Takahashi I. Vascular

528 endothelial growth factor expression in rat skin incision wound. Medical molecular

529 morphology. 2007;40(2):82-7.

530 50. Jang K-J, Kim HK, Han MH, Oh YN, Yoon H-M, Chung YH, et al. Anti-

531 inflammatory effects of saponins derived from the roots of Platycodon grandiflorus in

532 lipopolysaccharide-stimulated BV2 microglial cells. International Journal of Molecular

533 Medicine. 2013;31(6):1357-66.

534 51. Lim A-K, Kim K-S, Park S-J, Hong J-H, Choi H-J, Kim D-I. Healing effects of

535 ginsenoside $\operatorname{Rg} 1$ on experimental open wound in rat. Journal of the Korean Society of Food

536 Science and Nutrition. 2010;39(10):1452-8.

537 52. Chatzigeorgiou A, Halapas A, Kalafatakis K, Kamper E. The use of animal models

538 in the study of diabetes mellitus. In vivo. 2009;23(2):245-58.

539

540

541

542

543

544

545

546

547

548

549

550

551

552 
Figure 1. Protocol for wound induction.

STZ-induced diabetic mice were orally administered red ginseng extract $(10 \mathrm{mg} / \mathrm{kg})$ and $\mathrm{Rg} 1$

557 (10 mg/kg). Wounds were made on day 0 and measured on days 1,4 , and 7 . Mice were sacrificed on days 4,7 , and 10 . Mice were randomly divided into three groups according to oral-administration treatment. G1: red ginseng extract treatment group (10 mg/kg/day, $n=27)$;

G2: Rg1 treatment group (10 mg/kg/day, $n=27)$; G3: control (PBS) group ( $0.3 \mathrm{~mL} / \mathrm{kg} / \mathrm{day}, n$ =27). STZ: streptozotocin, Rg1: ginsenoside Rg1.

Figure 2. Changes in wound size by date in MRSA-infected diabetic rats.

(A) Images of wound size on different dates. (B) Wound size measurements for each group. At each point, the wound healing rate changed compared to the first day of injury. Data are expressed as a percentage by measuring the wounds of the mice in each group. Data are expressed as mean \pm standard deviation $(n=9)$. MRSA: methicillin-resistant Staphylococcus aureus.

Figure 3. Histology and IHC analysis.

571 For histological analysis, the slides corresponding to days 4, 7, and 10 for each group were stained with hematoxylin and eosin (H\&E). IHC staining of VEGF and TGF- $\beta 1$ (important factors for wound healing) was observed. (A) Tissues from mice of each group sacrificed 4 days after injury (H\&E stain in the left panels, VEGF antibody IHC stain in the middle panels, and TGF- $\beta 1$ antibody IHC stain in the right panels). (B) Tissues from mice of each group 
sacrificed 7 days after injury. (C) Tissues from mice of each group sacrificed 10 days after

577 injury. The original magnifications of $200 \times$ and $400 \times($ bottom panel) are displayed. (*) Position

of the granulation tissue and wound. (D) The degree of granulation tissue formation and infiltration of inflammatory cells were scored to objectify as H\&E stain (Tables 2 and 3). An objective scoring table shows that repeated scoring of three times was performed by blind test. IHC staining shows hematoxylin (blue) and VEGF and TGF- $\beta 1$ antibody (brown). Mice were divided into three groups (red ginseng extract group, Rg1 group, and the PBS-treated group as a control). ${ }^{*} \mathrm{p}<0.05$ compared to the control group and $\# \mathrm{p}<0.05$ compared to the treatment group. E: epidermis, D: dermis, TGF: transforming growth factor, VEGF: vascular endothelial growth factor.

Figure 4. Effects of red ginseng extract and $\mathrm{Rg} 1$ on the expression of VEGF and TGF- $\beta 1$ in diabetic wounds indicated by reverse transcription polymerase chain reaction (RT-PCR) analysis. (A) RT-PCR was performed for the tissue of diabetic mice using VEGF and TGF- $\beta 1$ primers. GAPDH was used to normalize the intensity of the analyzed bands. (B-C) mRNA expression of VEGF and TGF- $\beta 1$ increased significantly and then decreased during the woundhealing period (4-10 days after wound injury) in the red ginseng extract group; expression of VEGF and TGF- $\beta 1$ increased gradually in the Rg1 group. Significance was determined using the Mann-Whitney U test. Mice were divided into three groups (red ginseng extract group, Rg1 group, PBS-treated group as a control group). ${ }^{*} \mathrm{p}<0.05$ compared to the control group and $\# \mathrm{p}<0.05$ compared to the treatment group. TGF: transforming growth factor, VEGF: vascular endothelial growth factor, GAPDH: glyceraldehyde-3-phosphate dehydrogenase. 
599 Figure 5. Effects of red ginseng extract and $\operatorname{Rg} 1$ on the expression of VEGF and TGF- $\beta 1$ in 600 diabetic wounds indicated by western blot analysis. (A) Immunoblotting was performed for 601 diabetic mouse tissue using VEGF and TGF- $\beta 1$ antibodies. $\beta$-actin was used to normalize the 602 intensity of the analyzed bands. (B-C) Protein expression of VEGF and TGF- $\beta 1$ increased 603 significantly in the red ginseng extract and $\operatorname{Rg} 1$ groups during the wound healing period (4-10 604 days after injury) and then decreased with time. Significance was determined using the Mann605 Whitney U test. Mice were divided into three groups (red ginseng extract group, Rg1 group, PBS-treated group as a control group). ${ }^{*} \mathrm{p}<0.05$ compared to the control group and $\# \mathrm{p}<0.05$ compared to the treatment group. TGF: transforming growth factor, VEGF: vascular endothelial growth factor, $\beta$-actin: beta-actin. 
Tables

627

Table 1. Reverse transcription-polymerase chain reaction primer sequence.

629

VEGF, vascular endothelial growth factor; TGF- $\beta 1$, transforming growth factor- $\beta 1$; GAPDH, glyceraldehyde-3-phosphate dehydrogenase. 1)All primers were designed directly and purchased from Macrogen Corporation (Seoul, Republic of Korea). The primers for VEGF, TGF- $\beta 1$, and GAPDH used in this experiment are shown in the table and reverse transcriptionpolymerase chain reaction was performed using each primer.

634

\section{Target primer ${ }^{1)}$}

Oligonucleotide (5' to 3')

Size

VEGF

Forward: CAG GCT GCT GTA ACG ATG AA

$221 \mathrm{bp}$

Reverse: AAT GCT TTC TCC GCT CTG A

TGF- $\beta 1$

Forward: ATT CAG CGC TCA CTG CTC TT

$219 \mathrm{bp}$

Reverse: TTC TCT GTG GAG CTG AAG CA

GAPDH

Forward: CCT TAA ACA GGC CCA CTT GA

$201 \mathrm{bp}$

Reverse: CCT TCC ACA ATG CCA AAG TT

635

636

637

638

639

640

641

642 
645 Table 2. Degree of granulation tissue of formation score.

646 The degree of granulation tissue formation was scored in mouse skin tissue. Hematoxylin and 647 eosin staining were used to evaluate the degree of granulation formation histologically.

648

\begin{tabular}{lcc}
\hline Judgment element & Standard & Score \\
\hline Not formation & 0 \\
Granulation tissue of formation & More than $2 / 3$ of defect area & 1 \\
& $1 / 3$ to $2 / 3$ of defect area & 2 \\
& Less than $1 / 3$ of defective area & 3 \\
\hline
\end{tabular}


663 Table 3. Degree of inflammatory cells infiltration score.

664 The degree of infiltration of inflammatory cell was scored in mouse skin tissue. Hematoxylin 665 and eosin staining was performed histologically to evaluate the degree of infiltration of 666 inflammatory cell.

667

Inflammatory cell of infiltration cells are visible

When large clusters are formed and many 
Group treatments:

I: Red ginseng extract group $10 \mathrm{mg} / \mathrm{kg} / \mathrm{d}$

II: Ginsenoside Rg1 group $10 \mathrm{mg} / \mathrm{kg} / \mathrm{d}$

III: Control (PBS) group $0.3 \mathrm{ml} / \mathrm{kg} / \mathrm{d}$

Induced wounds

( $8 \mathrm{~mm}$ diameter)

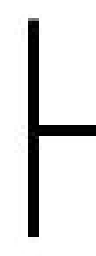

Day 0
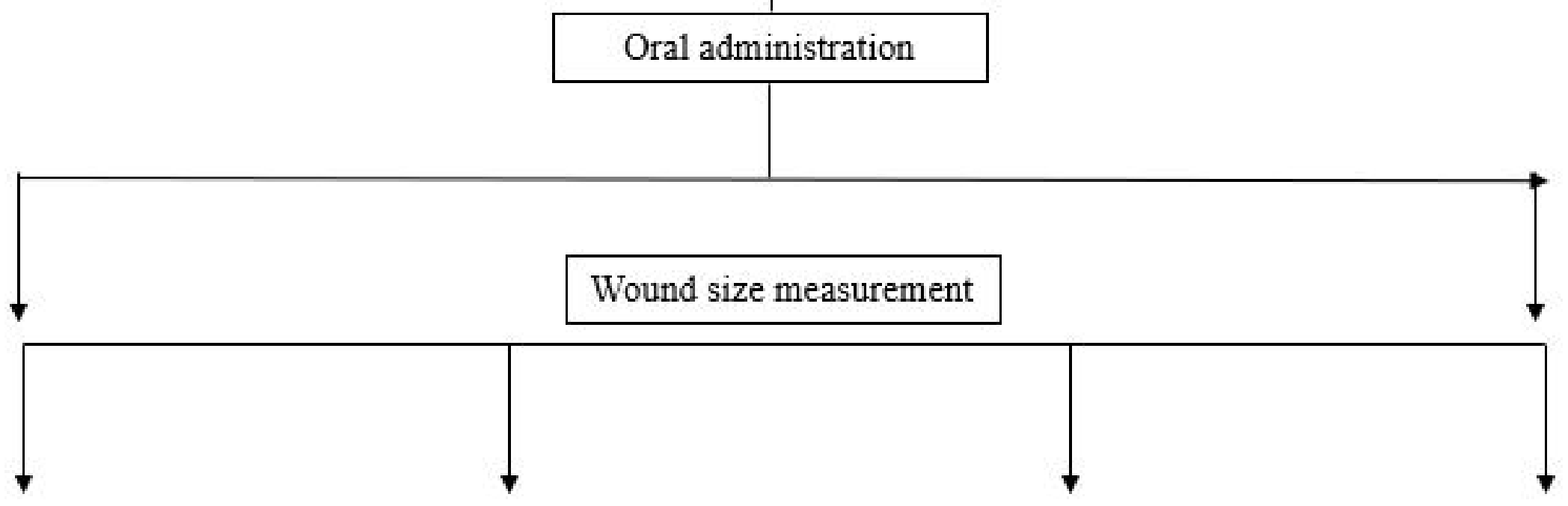

C.

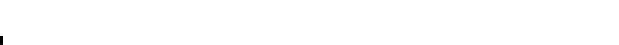

!
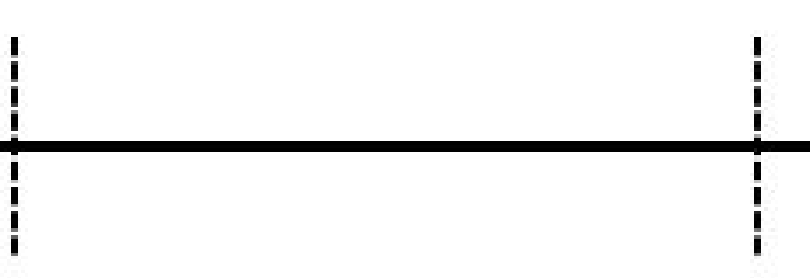

7 day

10 day

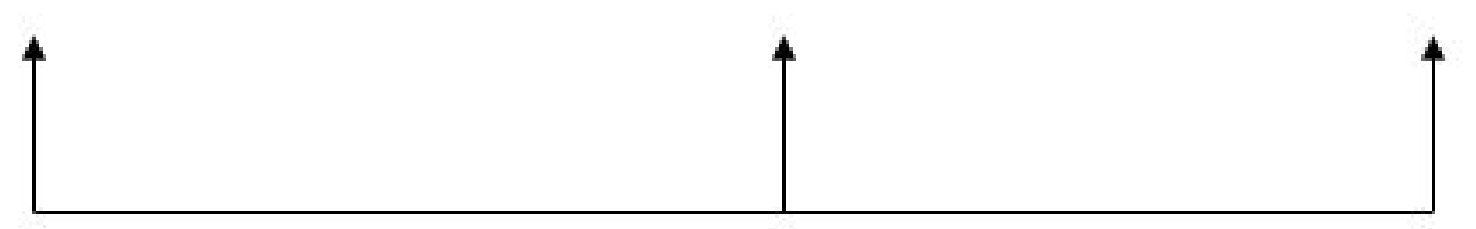

Sampling

Figure 1 


\section{Diabetic wounds}

Red ginseng extract group

Ginsenoside Rg1 group

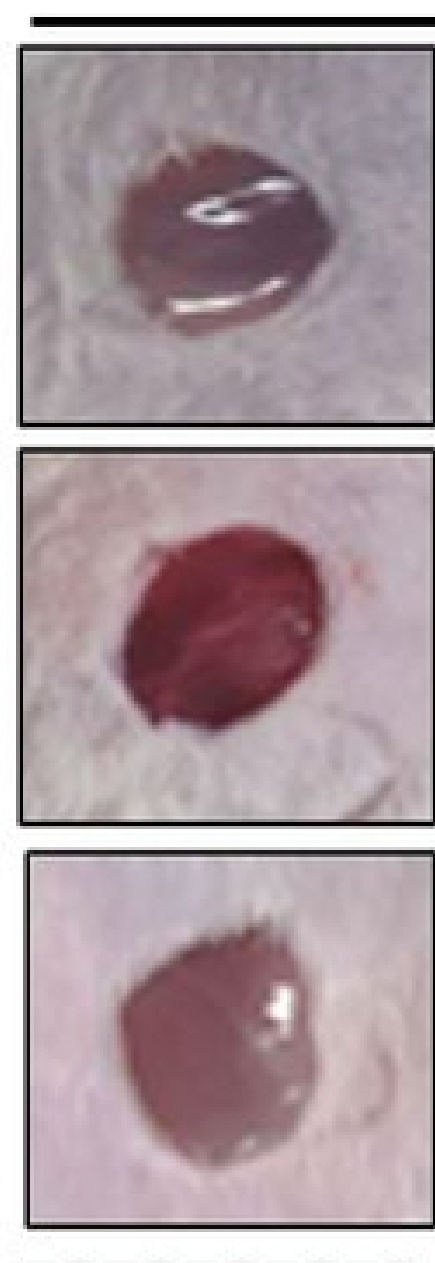

0 day
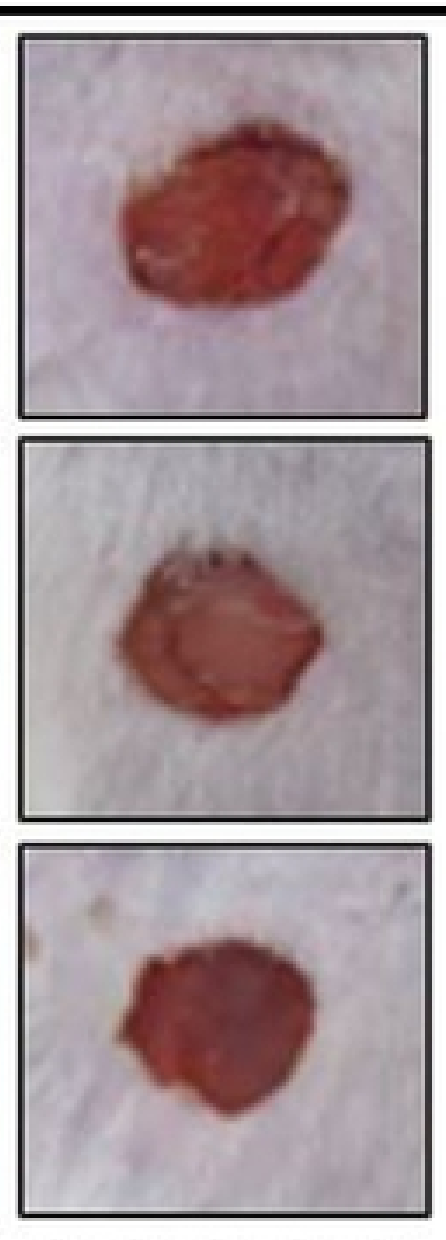

1 day
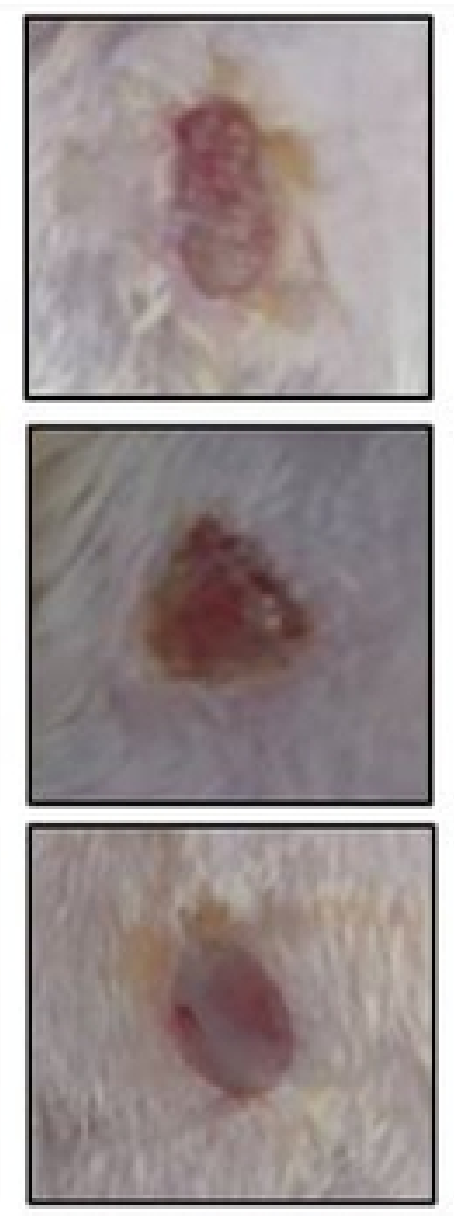

4 day
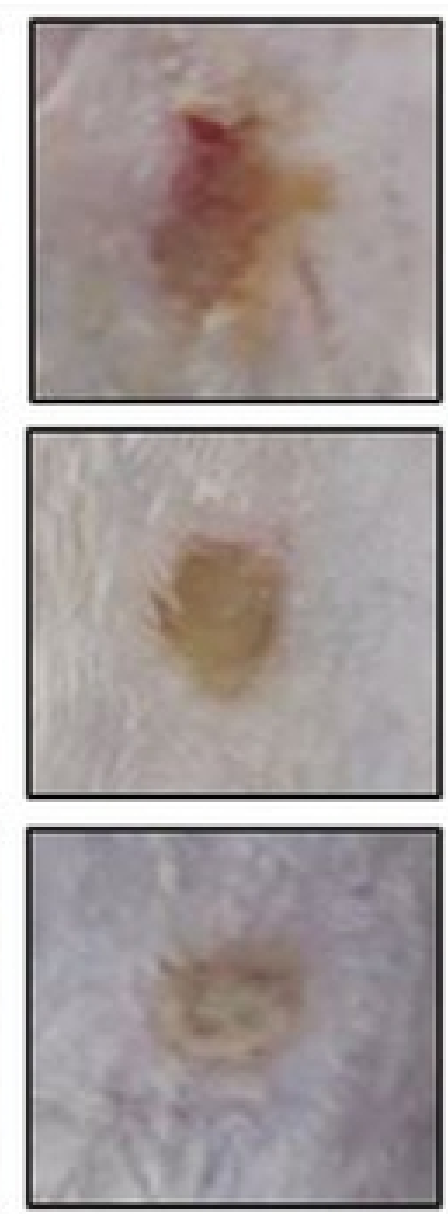

7 day
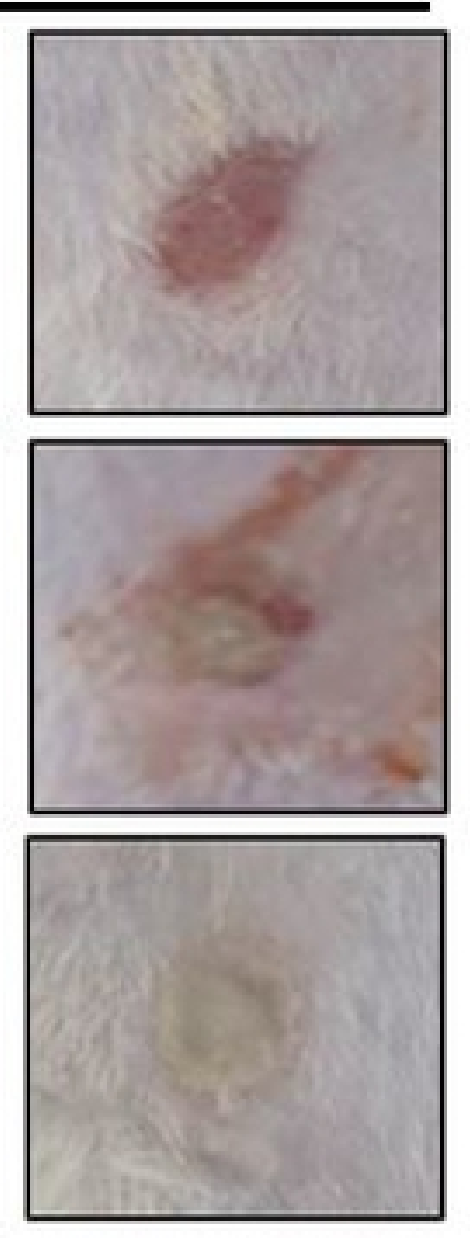

10 day

Figure $2 a$ 


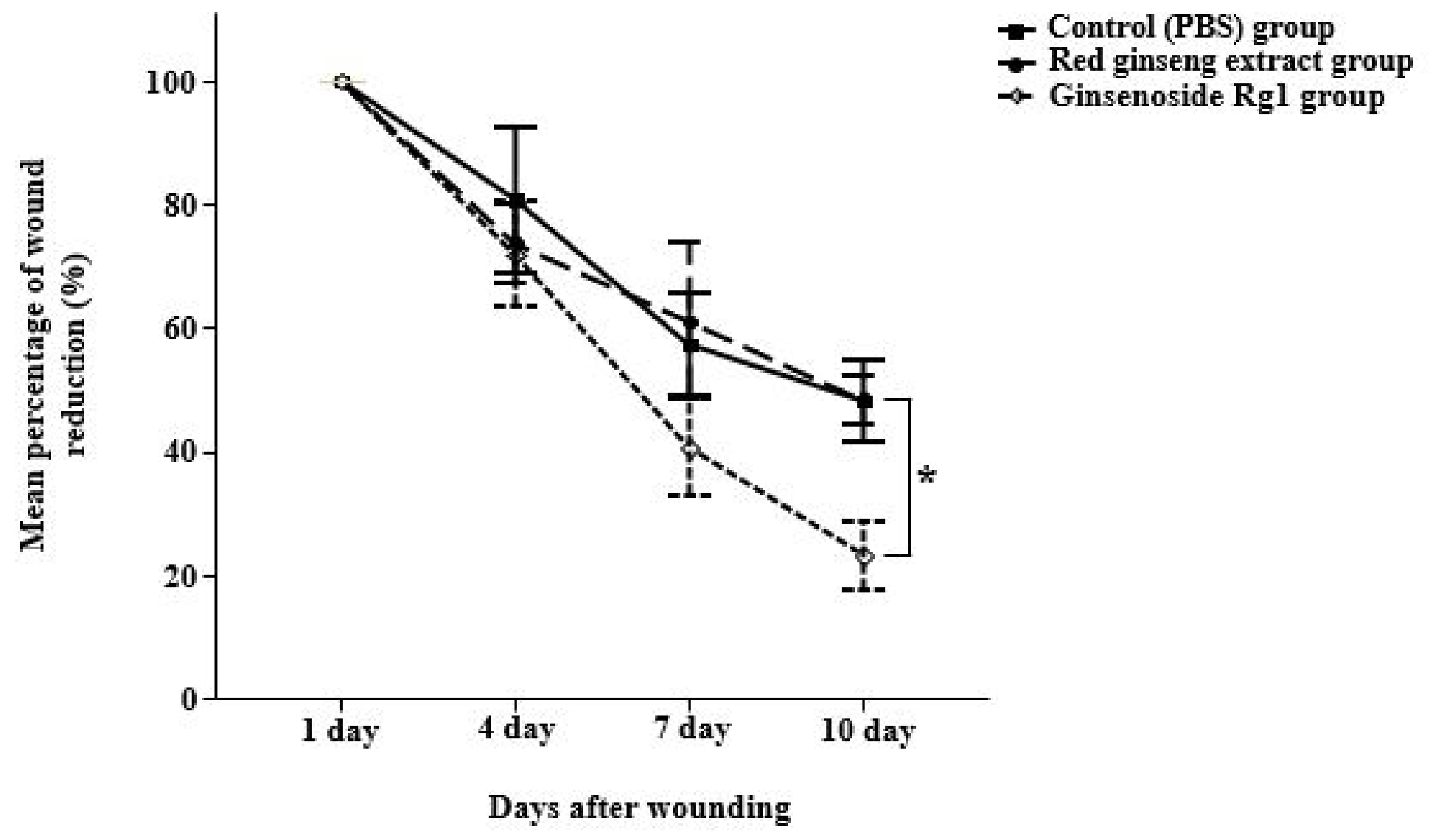

\section{Figure $2 b$}


A
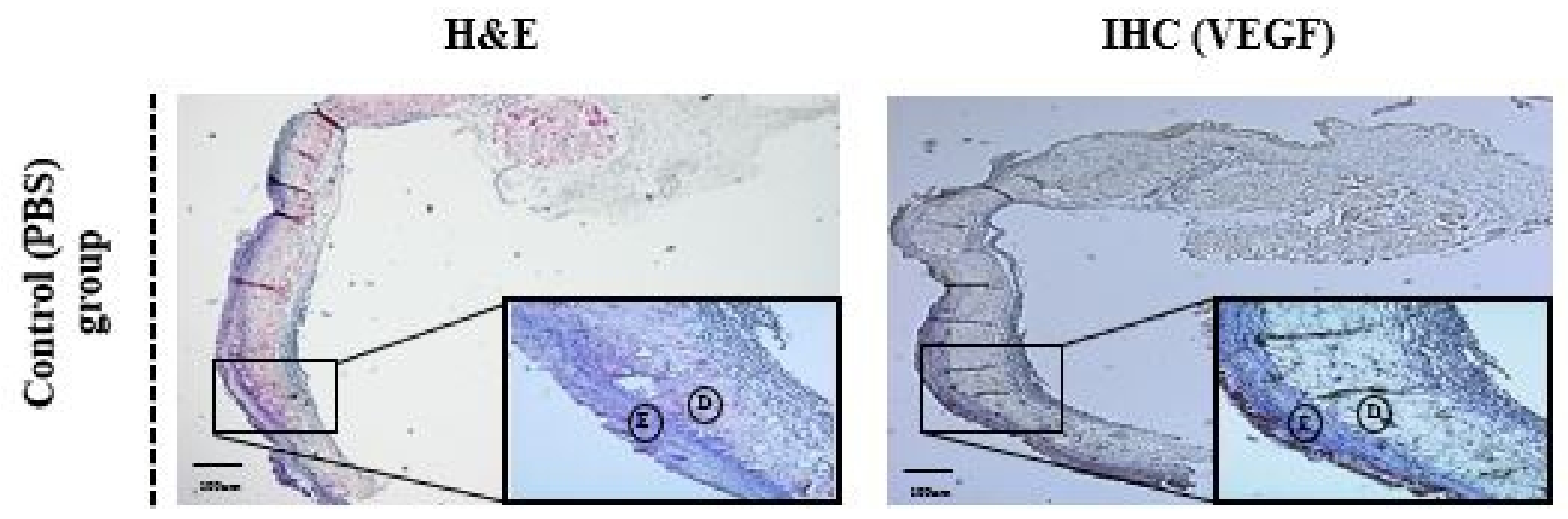

IHC (TGF- $\beta 1)$
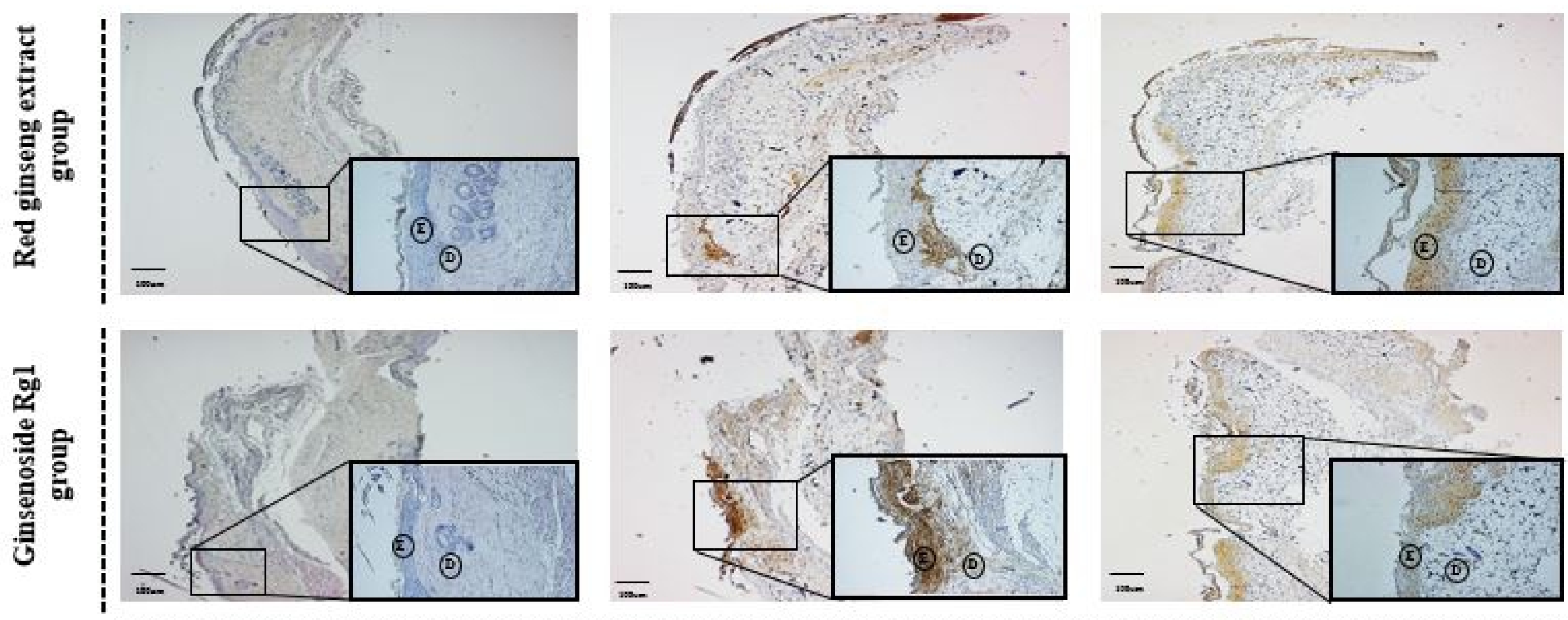

4 day

Figure 3a 
H\&E
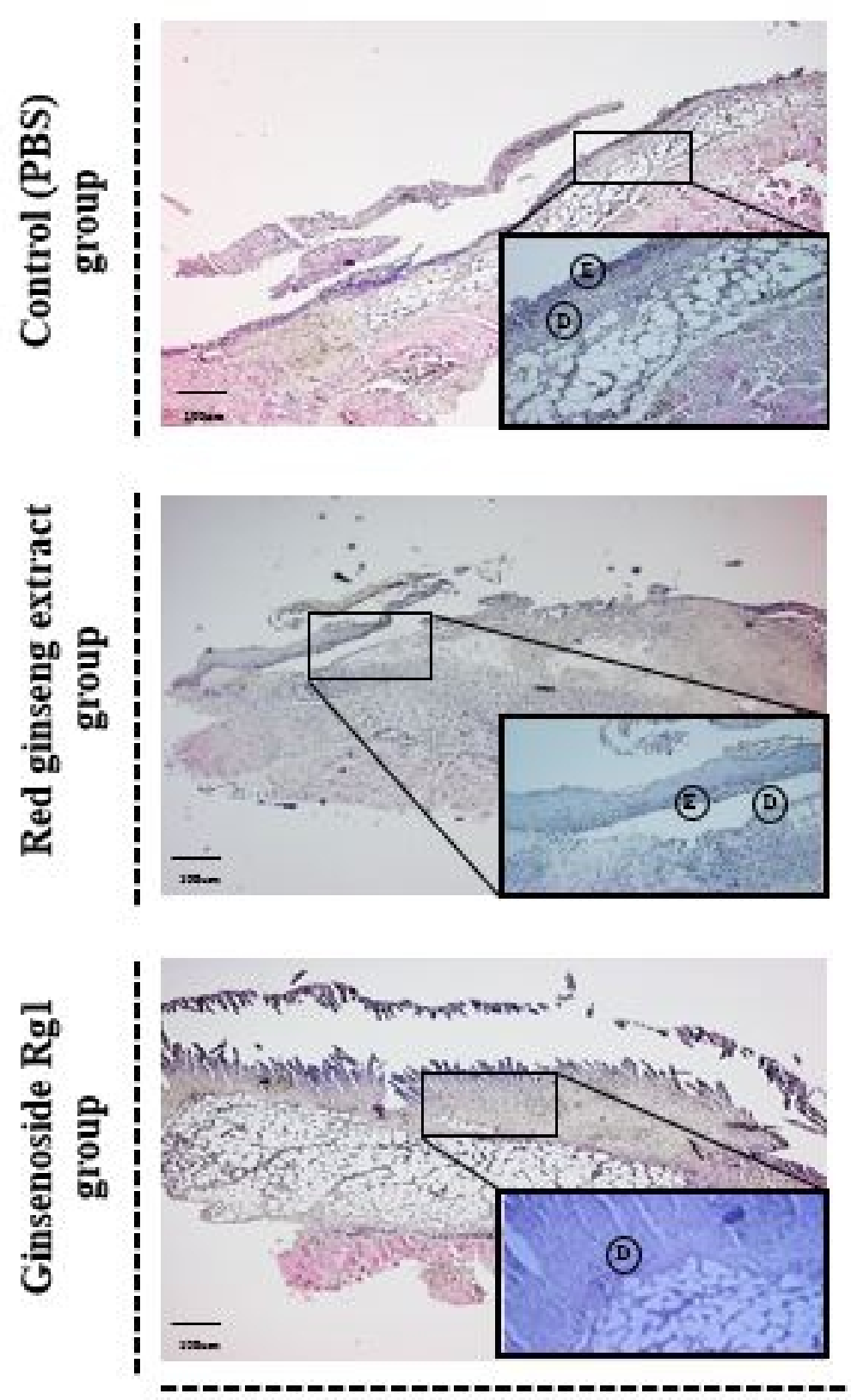

IHC (VEGF)
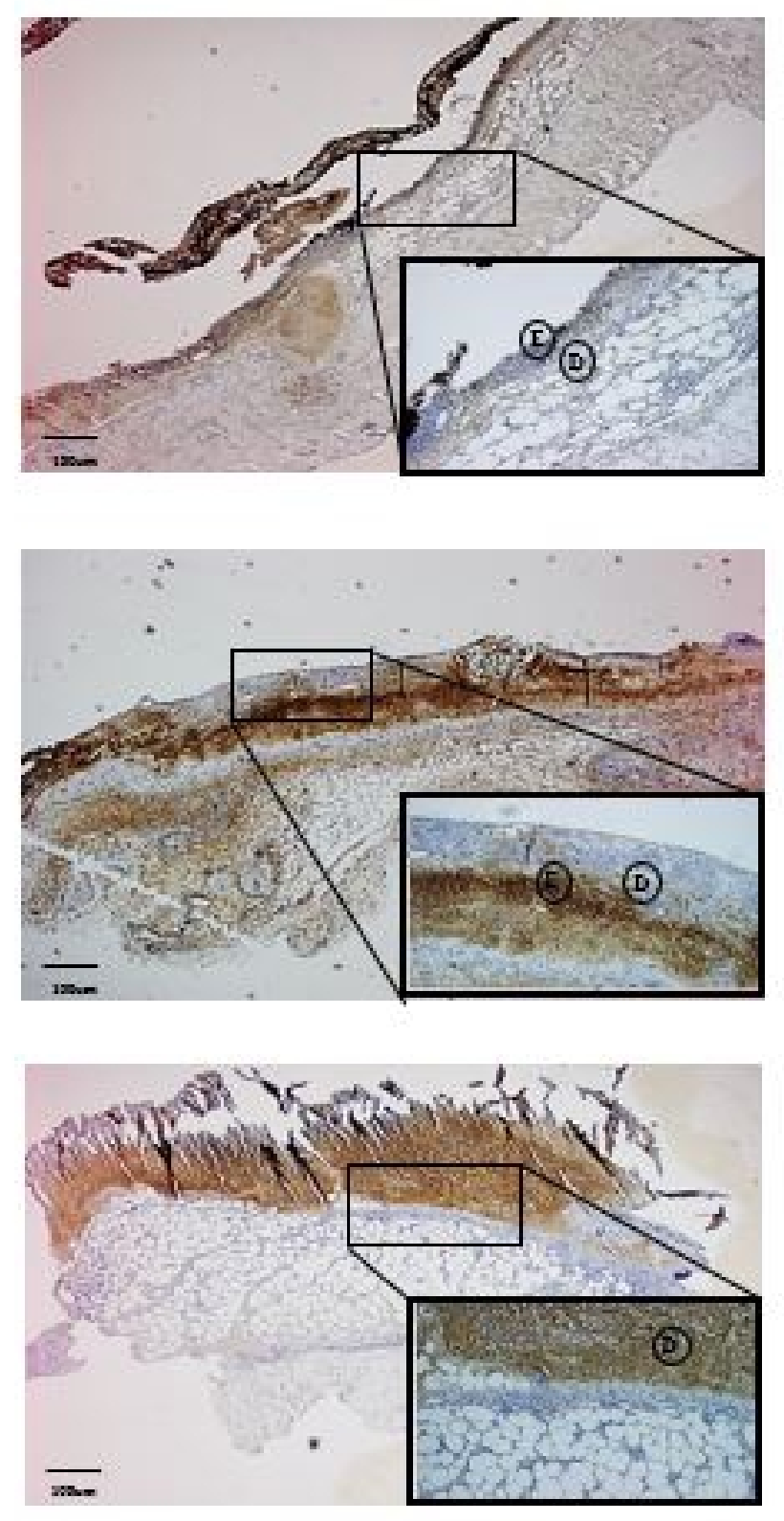

IHC (TGF- $\beta 1$ )
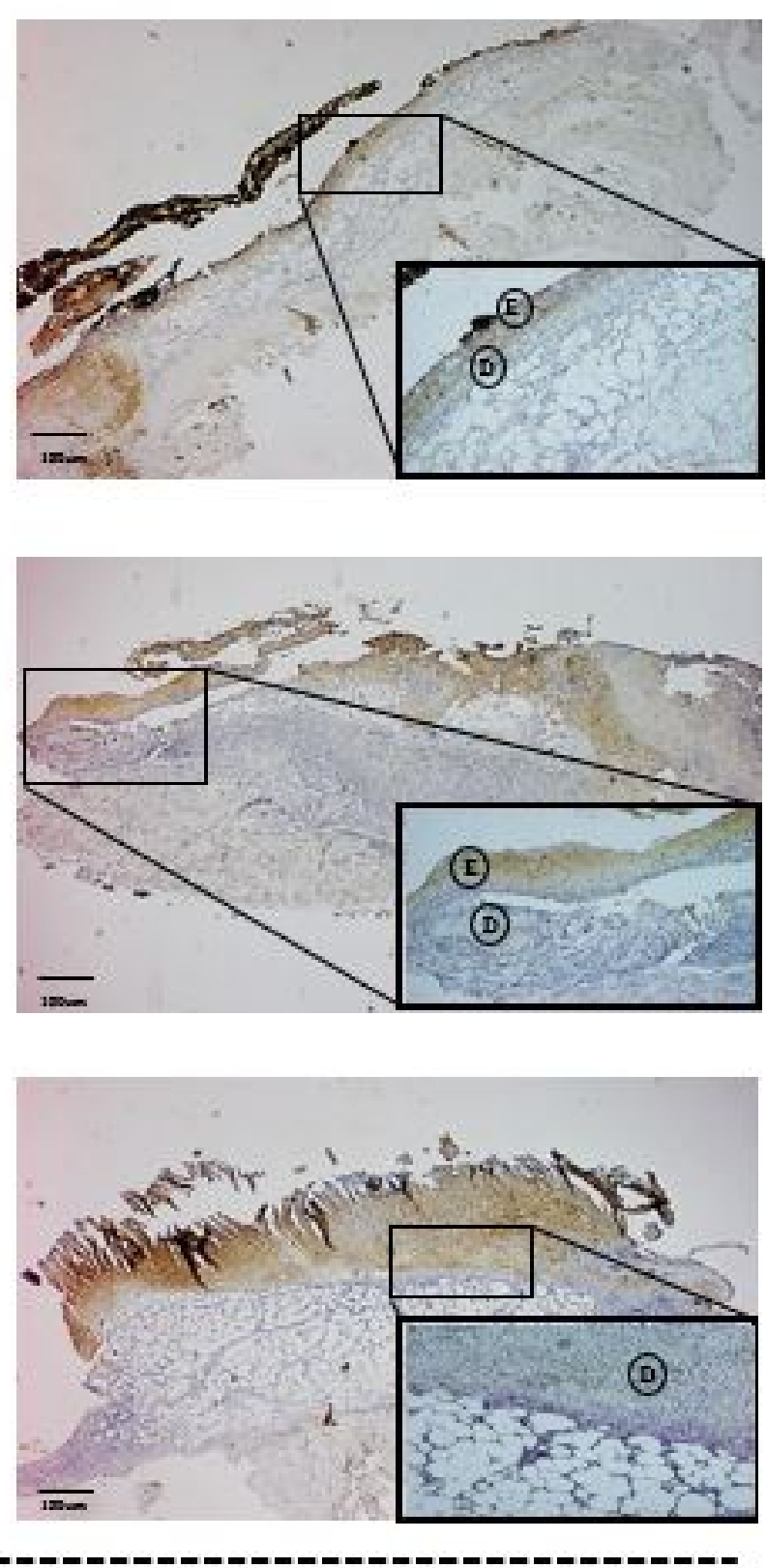

7 day

Figure $3 b$ 
H\&E
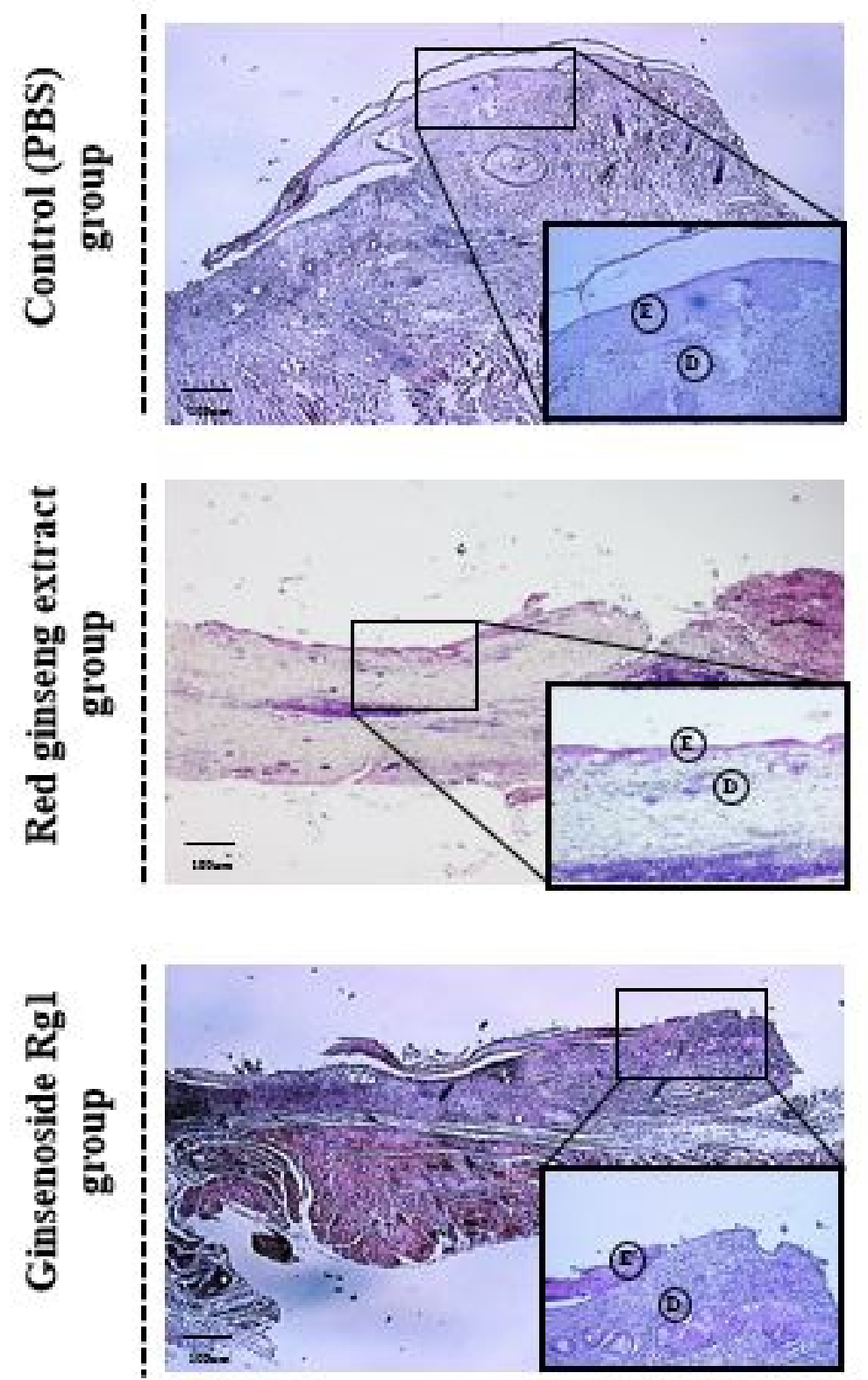

IHC (VEGF)
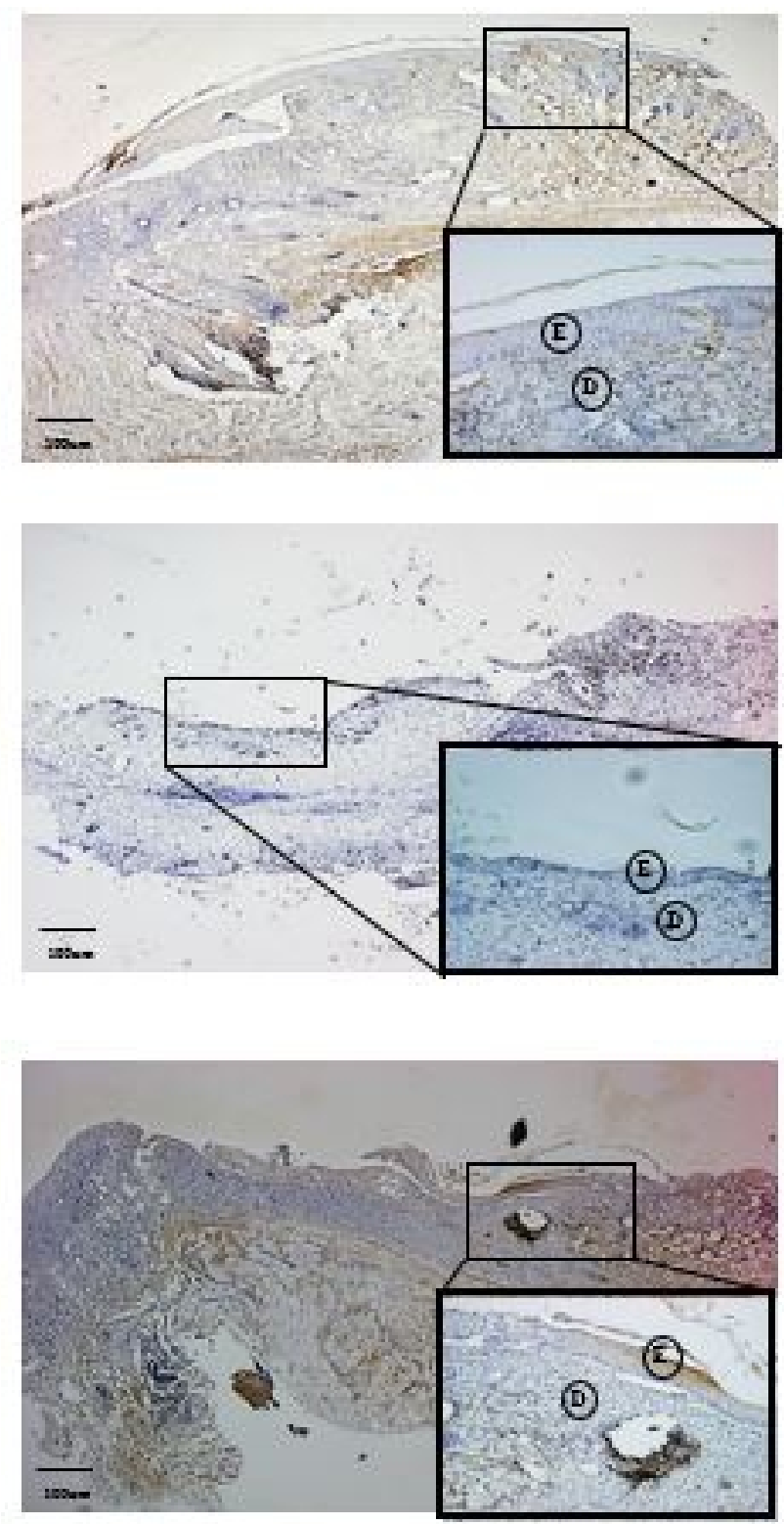

IHC (TGF- $\beta 1$ )
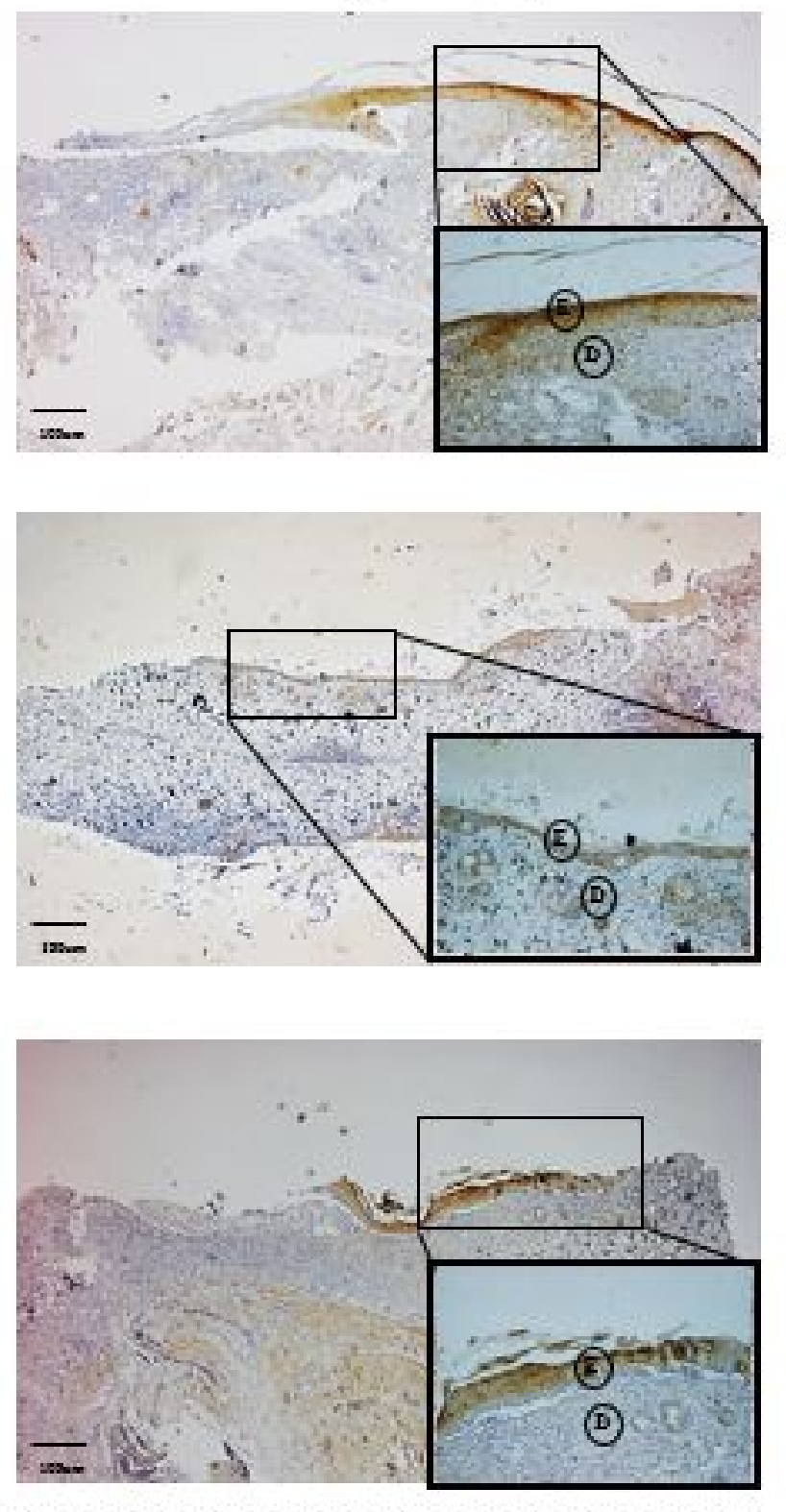

10 day

Figure $3 c$ 
D

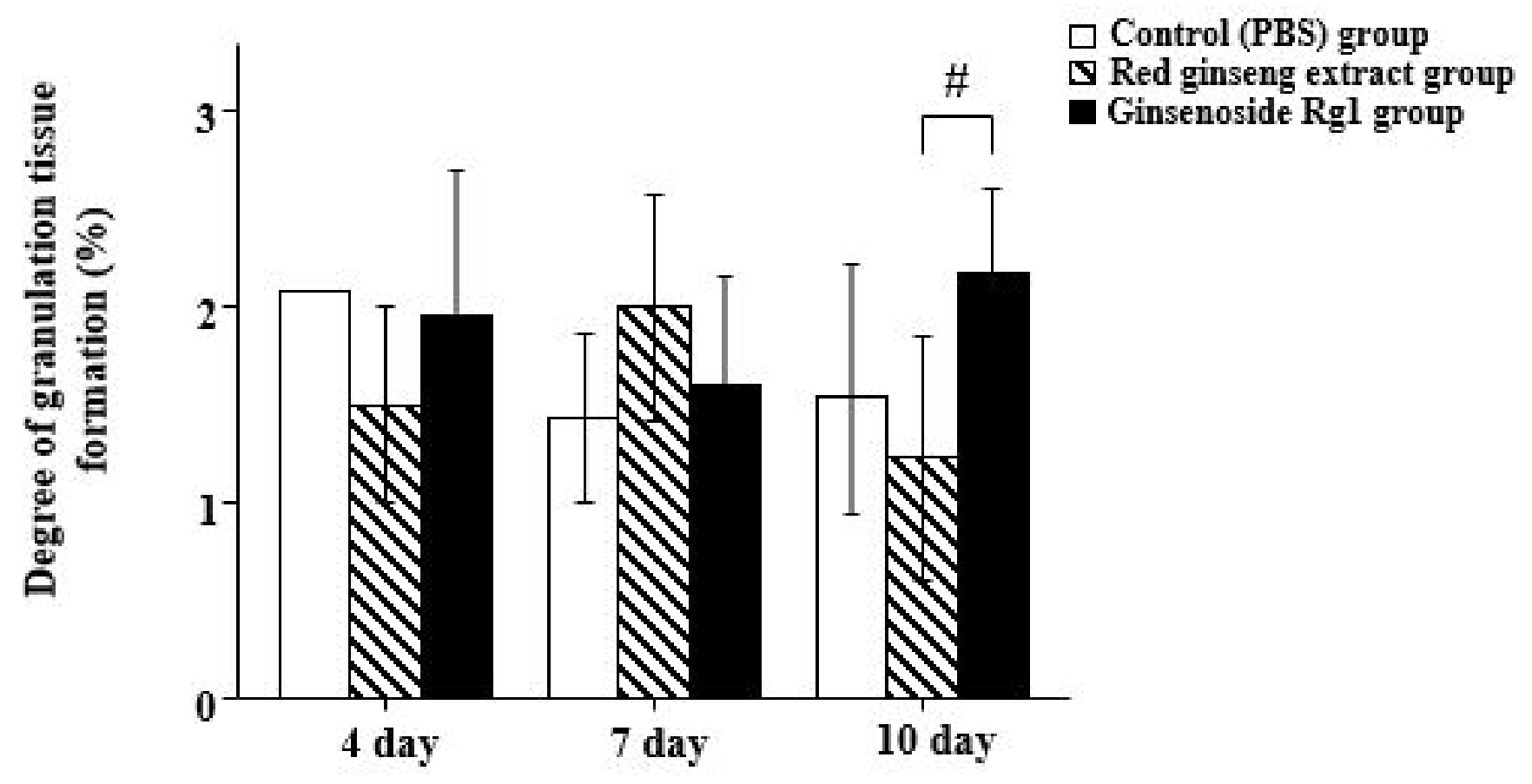

Days after wounding 
E

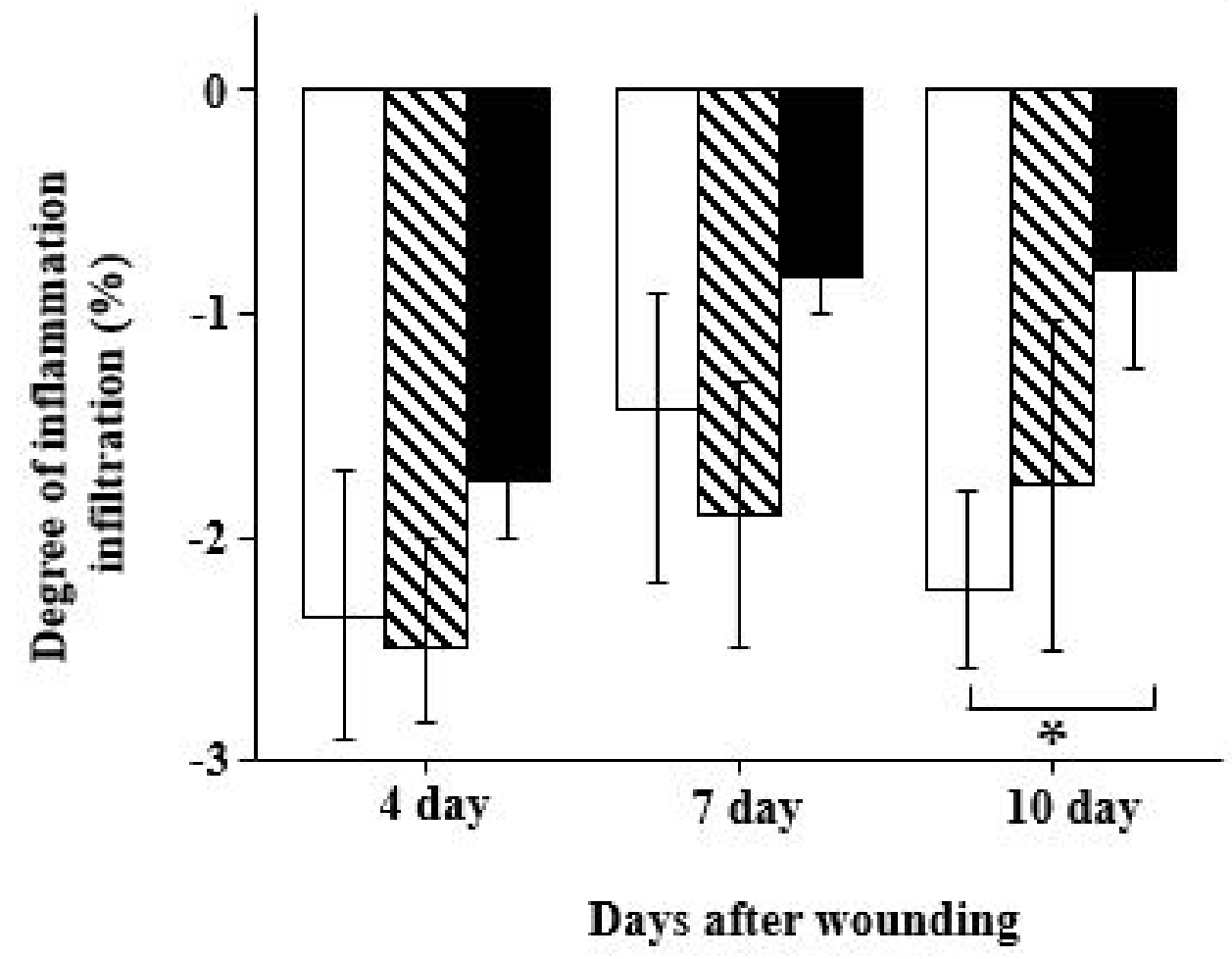

$\square$ Control (PBS) group

$\Delta$ Red ginseng extract group

口 Ginsenoside Rgl group 
A

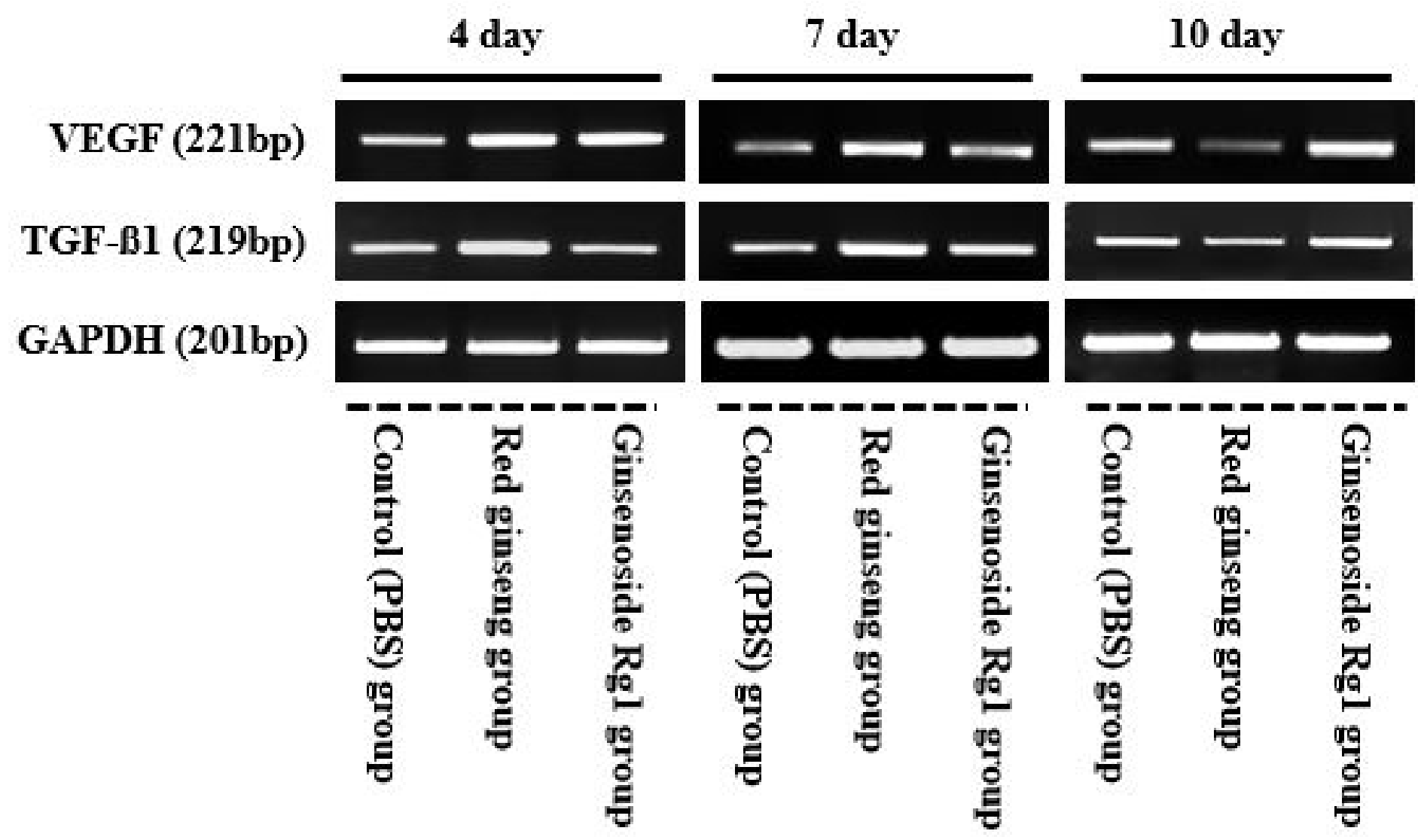

Figure 4a 
B

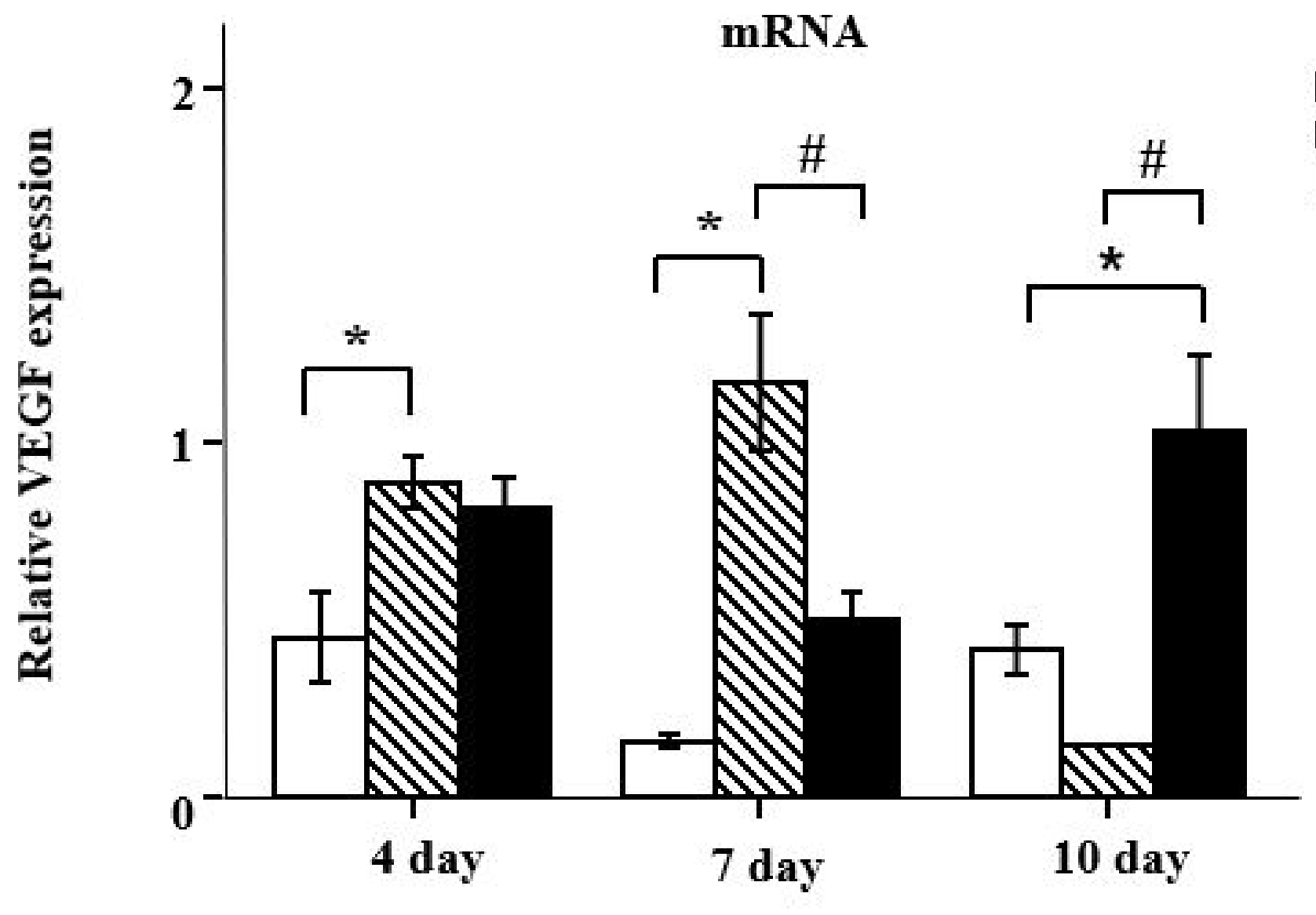

Control (PBS) group

$\nabla$ Red ginseng extract group

$\square$ Ginsenoside Rgl group

Days after wounding 
C

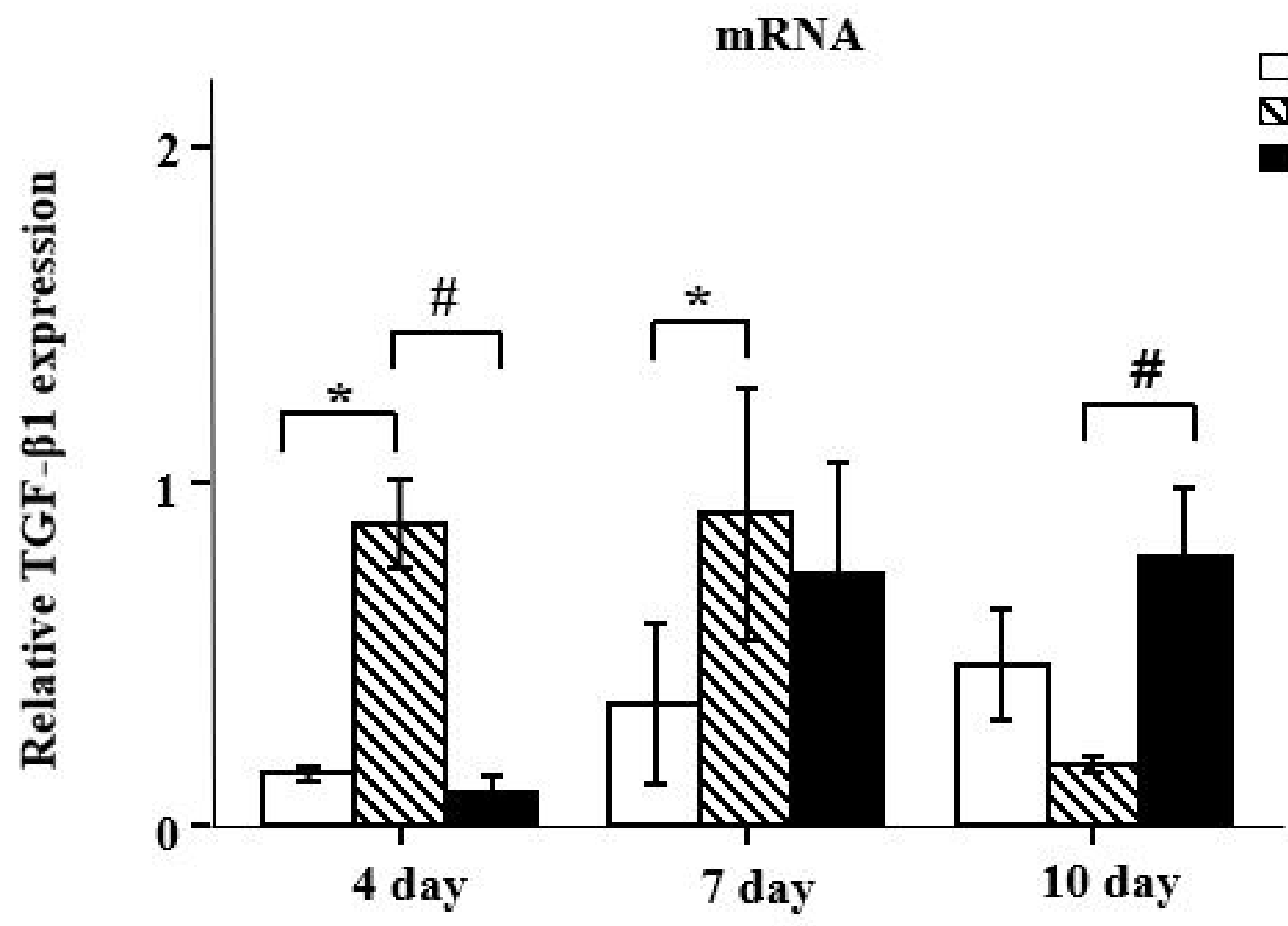

Days after wounding 
A

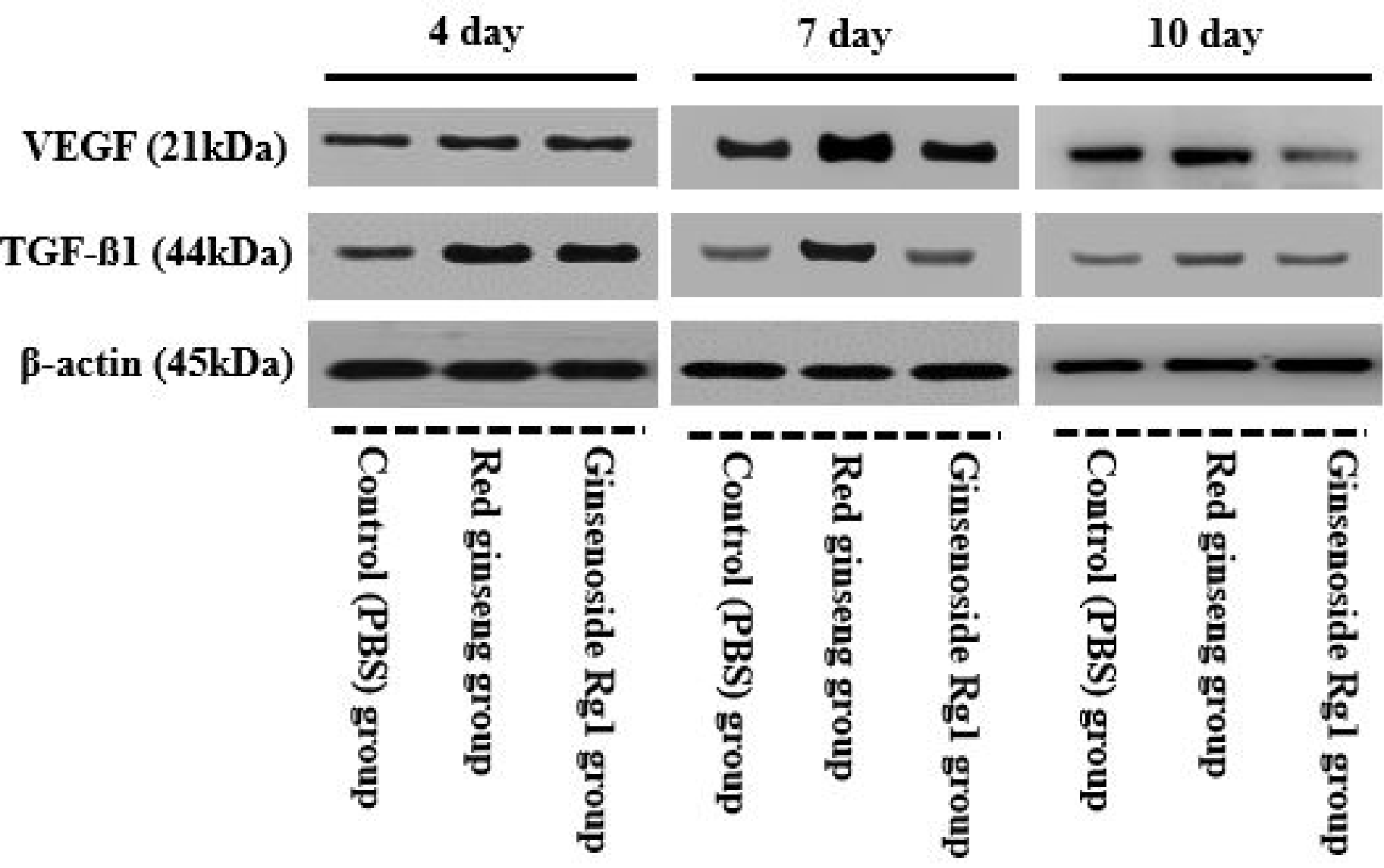

Figure $5 a$ 


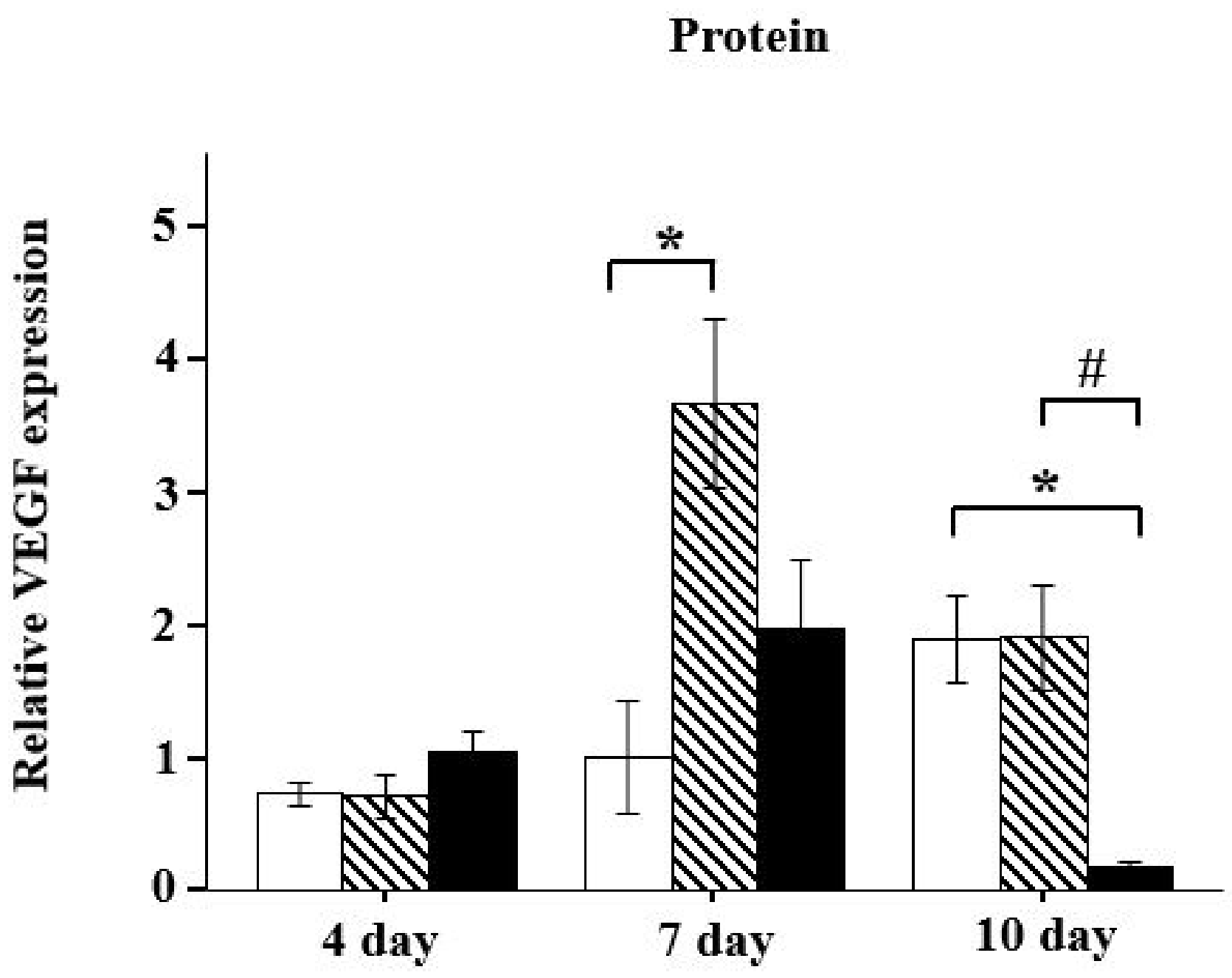

Control (PBS) group

$\Delta$ Red ginseng extract group

Ginsenoside Rg1 group

Days after wounding

Figure $5 b$ 


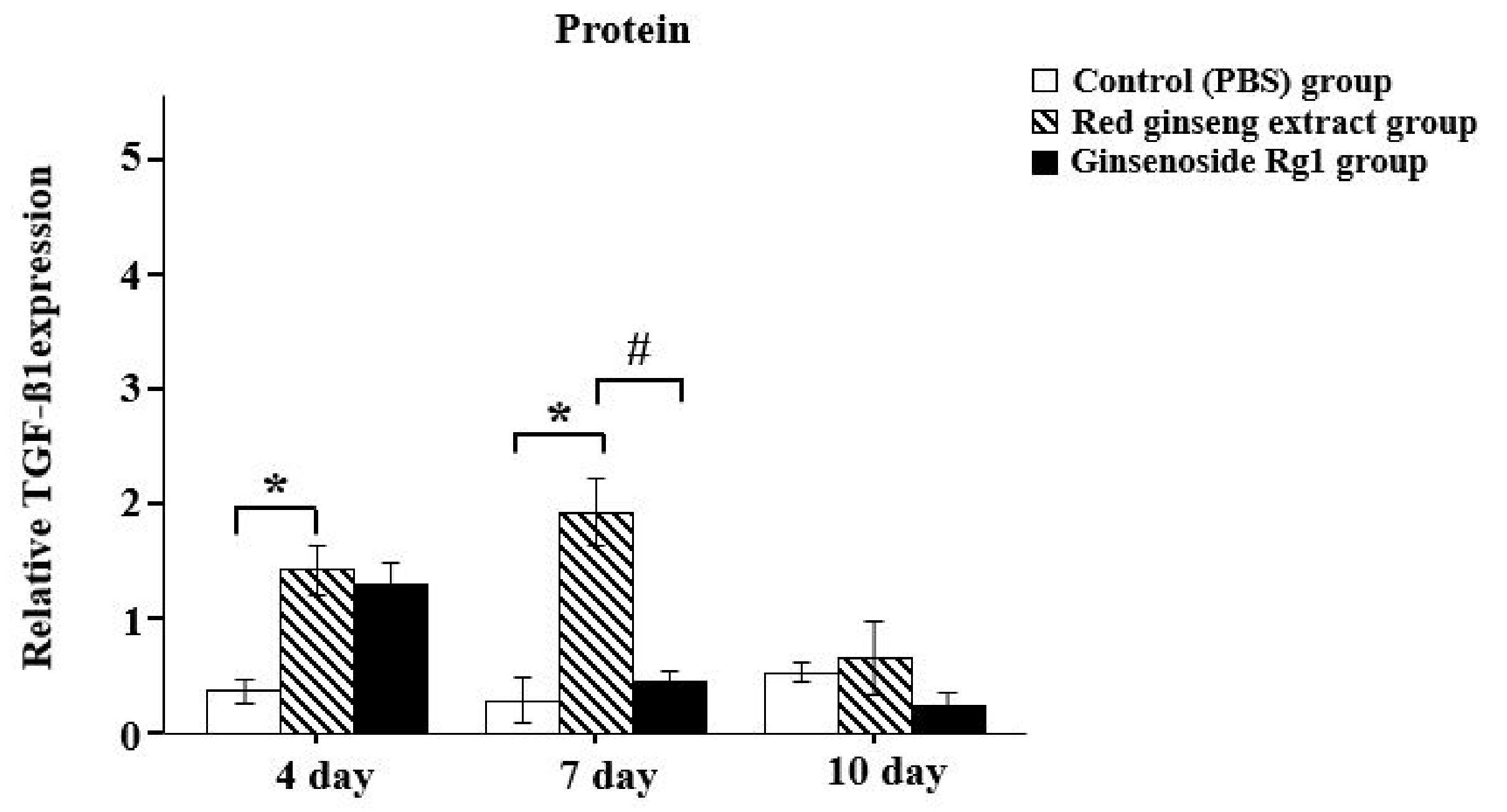

Days after wounding

Figure $5 c$ 